University of Tennessee Health Science Center

UTHSC Digital Commons

\title{
The Nucleolar Protein Nucleophosmin Undergoes Liquid-Liquid Phase Separation with Arginine-Rich Nucleolar Proteins through Weak, Multivalent Electrostatic Interactions
}

Jaclyn Alicia Cika

University of Tennessee Health Science Center

Follow this and additional works at: https://dc.uthsc.edu/dissertations

Part of the Biological Phenomena, Cell Phenomena, and Immunity Commons, and the Medical Cell Biology Commons

\section{Recommended Citation}

Cika, Jaclyn Alicia (http://orcid.org/0000-0003-2911-5648), "The Nucleolar Protein Nucleophosmin Undergoes Liquid-Liquid Phase Separation with Arginine-Rich Nucleolar Proteins through Weak, Multivalent Electrostatic Interactions" (2016). Theses and Dissertations (ETD). Paper 411.

http://dx.doi.org/10.21007/etd.cghs.2016.0414.

This Thesis is brought to you for free and open access by the College of Graduate Health Sciences at UTHSC Digital Commons. It has been accepted for inclusion in Theses and Dissertations (ETD) by an authorized administrator of UTHSC Digital Commons. For more information, please contact jwelch30@uthsc.edu. 


\title{
The Nucleolar Protein Nucleophosmin Undergoes Liquid-Liquid Phase Separation with Arginine-Rich Nucleolar Proteins through Weak, Multivalent Electrostatic Interactions
}

\author{
Abstract \\ Nucleoli are nuclear membrane-less organelles that are the sites for ribosome biogenesis and serve as \\ sensors of cellular stress. Weak, multivalent protein-protein interactions and interactions between \\ disordered, low complexity domains (LCDs) and rRNA have been shown to promote liquid-liquid phase \\ separation (LLPS) in vitro, suggesting a basis for the liquid-like behavior of nucleoli. Nucleophosmin \\ (NPM1), a multifunctional and highly abundant nucleolar protein, exhibits structural features associated \\ with LLPS suggesting a role in nucleolar organization. Specifically, NPM1 forms a pentamer through its N- \\ terminal oligomerization domain and can bind to rRNA through its $\mathrm{C}$-terminal nucleic acid binding \\ domain. Multiple acidic tracts throughout NPM1, two within an intrinsically disordered region (IDR), confer \\ additional multivalency and mediate interactions with proteins that contain multiple arginine-rich motifs \\ (R-proteins). Using a variety of techniques, we have identified several nucleolar R-proteins which bind to \\ and phase separate with NPM1. Here we show that the liquid-like properties of NPM1 droplets can be \\ tuned by modulating the extent of electrostatic interactions within the droplet. We propose that a \\ hierarchy of R-motifs, varying in valency and affinity, within nucleolar R-proteins exists which leads to a \\ heterogeneous network of interactions between proteins and rRNA within nucleoli, thus promoting \\ formation of a dynamic liquid-like phase conducive to ribosome biogenesis and other nucleolar functions. \\ Document Type \\ Thesis \\ Degree Name \\ Master of Science (MS) \\ Program \\ Biomedical Sciences \\ Research Advisor \\ Richard Kriwacki, Ph.D. \\ Keywords \\ Membrane-less organelle, Nucleolus, Phase Separation, Structural Biology

\section{Subject Categories} \\ Biological Phenomena, Cell Phenomena, and Immunity | Medical Cell Biology | Medical Sciences | \\ Medicine and Health Sciences
}


The Nucleolar Protein Nucleophosmin Undergoes Liquid-Liquid Phase Separation with Arginine-Rich Nucleolar Proteins through Weak, Multivalent Electrostatic Interactions

\author{
A Thesis \\ Presented for \\ The Graduate Studies Council \\ The University of Tennessee \\ Health Science Center
}

\author{
In Partial Fulfillment \\ Of the Requirements for the Degree \\ Master of Science \\ From The University of Tennessee
}

By

Jaclyn Alicia Cika

December 2016 
Copyright ( 2016 by Jaclyn Alicia Cika. All rights reserved. 


\section{ACKNOWLEDGEMENTS}

I would like to thank my mentor, Dr. Richard Kriwacki, for all of his guidance and support of the past three years. Thank you for taking me on as student, giving me multiple opportunities to develop my skills as a young scientist and for your understanding throughout this journey. I would also like to thank all of the members of the Kriwacki lab for helping me get started with my project and helping me with day to day tasks. I would like to express my gratitude to my fellow lab member, Dr. Diana Mitrea, for all of her help and discussions involving my project.

I would also like to acknowledge my committee members, Dr. J. Paul Taylor, Dr. Tanja Mittag, Dr. Brenda Schulman, and Dr. Susan Senogles for giving me valuable feedback and suggestions which have helped me write this thesis.

I would also like to thank my friends and family, especially my son Bryce, who have supported me along the way. 


\begin{abstract}
Nucleoli are nuclear membrane-less organelles that are the sites for ribosome biogenesis and serve as sensors of cellular stress. Weak, multivalent protein-protein interactions and interactions between disordered, low complexity domains (LCDs) and rRNA have been shown to promote liquid-liquid phase separation (LLPS) in vitro, suggesting a basis for the liquid-like behavior of nucleoli. Nucleophosmin (NPM1), a multifunctional and highly abundant nucleolar protein, exhibits structural features associated with LLPS suggesting a role in nucleolar organization. Specifically, NPM1 forms a pentamer through its N-terminal oligomerization domain and can bind to rRNA through its $\mathrm{C}$-terminal nucleic acid binding domain. Multiple acidic tracts throughout NPM1, two within an intrinsically disordered region (IDR), confer additional multivalency and mediate interactions with proteins that contain multiple arginine-rich motifs (R-proteins). Using a variety of techniques, we have identified several nucleolar R-proteins which bind to and phase separate with NPM1. Here we show that the liquidlike properties of NPM1 droplets can be tuned by modulating the extent of electrostatic interactions within the droplet. We propose that a hierarchy of R-motifs, varying in valency and affinity, within nucleolar R-proteins exists which leads to a heterogeneous network of interactions between proteins and rRNA within nucleoli, thus promoting formation of a dynamic liquid-like phase conducive to ribosome biogenesis and other nucleolar functions.
\end{abstract}




\section{TABLE OF CONTENTS}

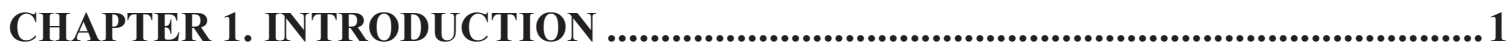

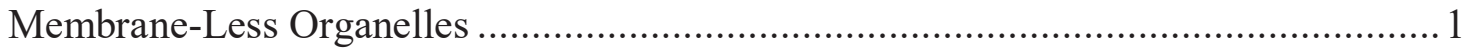

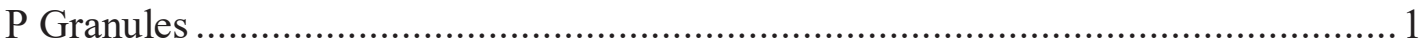

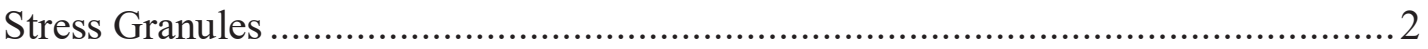

Liquid-Liquid Phase Separation ................................................................... 2

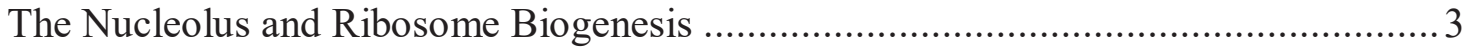

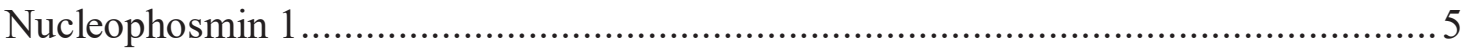

CHAPTER 2. MATERIALS AND METHODS .......................................................8

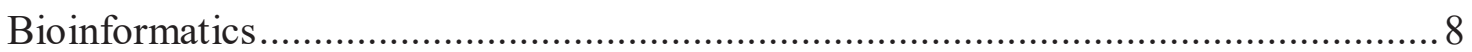

Cloning, Protein Expression, and Purification..................................................... 8

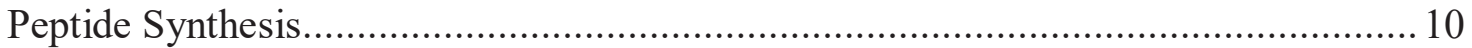

Determination of Protein, Peptide, and RNA Concentrations ................................... 10

Isothermal Titration Calorimetry ..................................................................... 10

Turbidity Measurements.................................................................................. 10

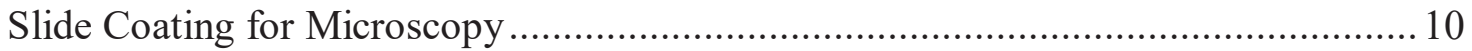

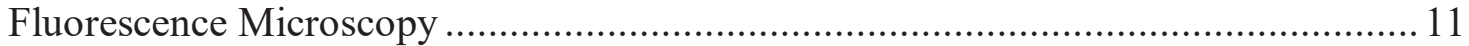

Fluorescence Recovery after Photobleaching ..................................................... 11

CHAPTER 3. RESULTS............................................................................ 13

Characterizing Features of NPM1 Binding Partners ........................................ 13

Survey for Droplet Formation with NPM1 and Peptides ....................................... 17

Survey for Droplet Formation with Longer Constructs and rRNA...........................2 21

Measuring Protein Dynamics within NPM1 and Arginine-Rich Nucleolar Protein

Droplets............................................................................................. 21

CHAPTER 4. DISCUSSION ..................................................................................... 30

NPM1 Interacts with a Variety of Arginine-Rich Motif Nucleolar Proteins through

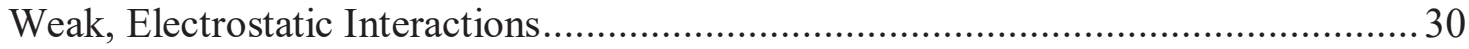

Weak, Multivalent Electrostatic Interactions Promote In Vitro Phase Separation ....... 31

NPM1 Phase Separates with Nucleolar Arginine-Rich Motif Containing Proteins

and rRNA to Form Liquid-Like In Vitro Droplets ................................................. 32

Protein Dynamics within Droplets Can Be Modulated by Electrostatic Interactions ... 34

Protein Dynamics within Droplets Can Be Modulated by rRNA ............................. 34

Future Directions .................................................................................. 36

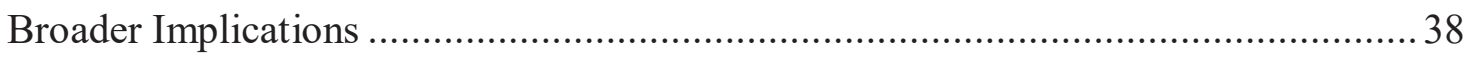

LIST OF REFERENCES ..............................................................................39

APPENDIX A. PROTEIN PURIFICATION ........................................................... 44

APPENDIX B. PROTEIN CHARACTERIZATION .............................................49 


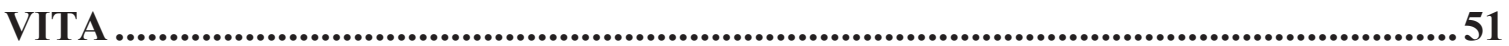




\section{LIST OF TABLES}

Table 3-1. Synthetic Peptides of NPM1 Binding Partners........................................ 14

Table 3-2. $\quad$ ITC Data for NPM1 with R-Peptides .................................................. 16

Table A-1. Protein Sequences ..................................................................... 44

Table B-1. Protein Molecular Weight and Extinction Coefficients ..........................50 


\section{LIST OF FIGURES}

Figure 1-1. Concentration Dependent Phase Diagram................................................. 4

Figure 1-2. Structural Features of Monomeric Nucleophosmin 1 .................................

Figure 1-3. Pentameric Structure of Nucleophosmin 1 ............................................. 7

Figure 3-1. ITC Curves for NPM1 with R-Peptides ……………………………..... 15

Figure 3-2. N130 Phase Separates with a Variety of R-Motifs Containing Peptides ..... 18

Figure 3-3. Linker Length Dictates N130 Droplet Size ................................................ 19

Figure 3-4. Phase Separation of R-Peptides with rRNA by Turbidity ...........................2 20

Figure 3-5. N294 Phase Separates with a Variety of R-Proteins ....................................22

Figure 3-6. rRNA Promotes LLPS with NPM1 and R-Proteins....................................23

Figure 3-7. Salt Dependence of Surf6/N294 Droplets ................................................25

Figure 3-8. Effects of Electrostatic Interactions of Surf6 Dynamics within

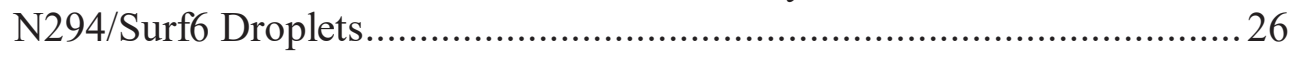

Figure 3-9. Effects of Electrostatic Interactions of N294 Dynamics within

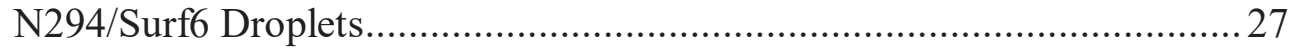

Figure 3-10. NPM1/GNL2 Droplets Can Be Modulated by the Addition of rRNA ........28

Figure 4-1. NPM1 Droplet Network Can Be Tuned by Modulating Electrostatic

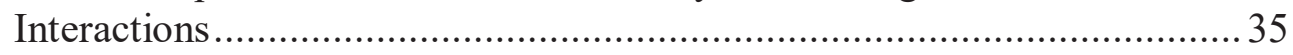

Figure 4-2. Protein Dynamics Can Be Tuned by the Addition of rRNA ……................ 37

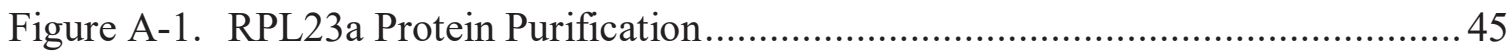

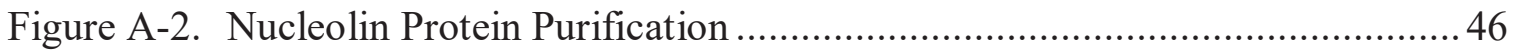

Figure A-3. GNL2 Protein Purification …………….............................................. 47

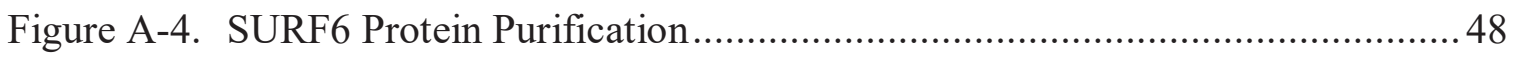

Figure B-1. RPL23a Structure Characterization .......................................................... 49

Figure B-2. CD Spectra of Purified R-Proteins............................................................... 49 


\section{LIST OF ABBREVIATIONS}

$\tau$

A-tract

CTD

$\mathrm{DFC}$

$\mathrm{DIC}$

FC

FRAP

$\mathrm{GC}$

GNL2

ITC

LLPS

NoLS

NLS

NPM1

OD

R-motif

R-peptide

R-protein

RPL23a

RPL5

rRNA

SURF6
Apparent FRAP Recovery Time

Acidic tract

C-terminal nucleic acid binding domain

Dense Fibrillar Component

Differential Interference Contrast

Fibrillar Center

Fluorescence Recovery after Photobleaching

Granular Component

Nucleolar GTP-binding protein 2

Isothermal Titration Calorimetry

Liquid-Liquid Phase Separation

Nucleolar Localization Signal

Nuclear Localization Signal

Nucleophosmin 1

Oligomerization Domain

Arginine-rich motif

Arginine-rich motif peptides

Arginine-rich motif proteins

Large ribosomal subunit protein 23a

Large ribosomal subunit protein 5

Ribosomal RNA

Surfeit locus protein 6 


\section{CHAPTER 1. INTRODUCTION}

Eukaryotic organisms harbor various organelles to separate macromolecules and enzymatic reactions within cells. These organelles are separated into two classes: membrane-bound, and membrane-less. Membrane-bound (e.g. mitochondria, nuclei, and the endoplasmic reticulum) are encapsulated in a lipid bilayer, which enables these organelles to maintain their localization of proteins, nucleic acids, and other biomolecules. The assembly, function, and maintenance of membrane-bound organelles has been studied extensively for years and is now better understood. In contrast, understanding of membrane-less organelles is currently limited. Yet, over the last few years a new field of science has emerged to close this gap, which focuses to understand the physical basis for the formation of membrane-less organelles, and how their components and biophysical properties are related to their structure and function.

\section{Membrane-Less Organelles}

Membrane-less organelles such as stress granules, Cajal bodies, and nucleoli, arise through reversible self-assembly of soluble proteins and nucleic acids (Burke, et. al., 2015; Guo, et. al., 2015; Nott, et. al., 2015; Weber and Brangwynne, 2012; Zhang, et. al., 2015). Additionally, many have been shown to behave like liquids in that they are spherical in nature, can fuse with like organelles, and their components are highly dynamic and can exchange with components outside of the organelle (Elbaum-Garfinkle, et. al., 2015; Molliex, et. al., 2015; Nott, et. al., 2015; Zhang, et. al., 2015). Furthermore, it has been suggested that the formation of these organelles occurs through phase separation of molecular components (Molliex, et. al., 2015; Weber and Brangwynne, 2015; Patel, et. al., 2015). As these organelles do not have a lipid membrane to separate their components from the nucleo- or cytoplasm, membrane-less organelles are able to respond to changes in the environment (Mitrea and Kriwacki, 2016). This characteristic may be the basis for why many membrane-less organelles are known to play a role in cell stress responses (Boisvert, et. al., 2007; Buchan, 2014; Cioce and Lamond, 2005; Fox and Lamond, 2010).

\section{P Granules}

The specific type of germ granules (i.e., the class of granules which dictate germcell specification) termed $\mathrm{P}$ granules are cytoplasmic ribonucleoprotein complexes found within Caenorhabditis elegans (Brangwynne, et. al., 2009; Schneider and Bowerman, 2003). Initially, P granules are distributed evenly throughout the one-cell embryo, however, once the cell prepares for meiotic division and becomes polarized, $\mathrm{P}$ granules become localized to the posterior half of the cell (Brangwynne, et. al., 2009). Asymmetrical localization and division allows for the maintenance of $\mathrm{P}$ granule positive progenitor cells and the creation of a P granule negative somatic sister cell (Brangwynne, et. al., 2009). This asymmetric localization of $P$ granules has been shown to be due to 
changes in local protein concentrations leading to dissolution and assembly of granules, respectively, in the different cellular locations rather than migration of $\mathrm{P}$ granules to one side of the cell (Brangwynne, et. al., 2009). This observation is what first led the field to propose a mechanism where membrane-less organelles are formed by liquid-liquid phase separation (LLPS) of their components. Further supporting this hypothesis, when mixed in vitro, the disordered $\mathrm{P}$ granule protein, LAF-1, and RNA phase separate to form liquidlike droplets (Elbaum-Garfinkle, et. al., 2015). Many groups subsequently found that disordered proteins and often RNA are critical for in vivo and in vitro LLPS (Weber and Brangwynne, 2012; Feric, et. al., 2016; Mitrea, et. al., 2016; Molliex, et. al., 2015).

\section{Stress Granules}

Stress granules are cytoplasmic granules composed of mRNA and proteins that form in response to stalled translation during cell stress (Anderson et .al., 2015; Molliex et. al., 2015; Buchan and Parker, 2009). Once stress signals are removed and translation has been re-initiated, stress granules dissolve (Mitrea and Kriwacki, 2015). In recent years, stress granules have been linked to various degenerative diseases such as amyotrophic lateral sclerosis, frontotemporal dementia, and inclusion body myopathy $(\mathrm{Li}$, et. al., 2013; Ramaswami, et. al., 2013). For instance, disease mutations found within low complexity domains (i.e., disordered regions comprised of only a few amino acids) of heterogeneous nuclear ribonucleoproteins A2B1 and A1 (hnRNPA2B1 and hnRNPA1, respectively) have been shown to promote their incorporation into stress granules and formation of fibrillar structures within cytoplasmic inclusions (Kim, et. al., 2013). Furthermore, it is believed that fibril formation is promoted over time, with extensive stress granule formation and dissolution, and that fibril formation is enhanced with the disease causing mutants (Molliex, et. al., 2015). Another stress granule protein harboring low complexity domains shown to be implicated in disease is the fused in sarcoma (FUS) RNA-binding protein (Burke, et. al., 2015; Sharma, et. al., 2015). Like hnRNPA2B1 and hnRNPA1, it is believed that low complexity regions of FUS (i.e., [G/S]Y[G/S] repeats) undergo fibril formation over time and contribute to the disease state of stress granules (Han, et. al., 2012; Kato, et. al., 2012).

\section{Liquid-Liquid Phase Separation}

As previously stated, unlike their lipid-bound cousins, membrane-less organelles do not have a physical barrier to separate their components from the surrounding nucleoor cytoplasm, which raises the questions as to how these organelles exist and why their components do not simply mix with the surrounding environment. Recently, it has been suggested that membrane-less organelles are able to form through concentrationdependent LLPS and therefore behave as liquids (Brangwynne, et. al., 2009; Han, et. al., 2012; Hyman, et. al., 2014; Molliex, et. al., 2015; Weber and Brangwynne, 2015). To be a liquid, components must be able to quickly and readily rearrange and exchange with components in the surrounding environment (Hyman, et. al., 2014). Components that make up the liquid-like membrane-less organelle interact with one another in a soluble 
one-phase state, but as the degrees of interactions are increased (e.g., through increases in protein concentration), a point is reached where it is more entropically favorable for the components to demix with the surrounding liquid environment to form a two-phase separated state (Figure 1-1), much like oil and water (Hyman, et. al., 2014).

Many proteins found within membrane-less organelles are disordered or contain disordered regions, which allows for increased protein flexibility and mobility and allows for rapid exchange into and out of the organelle, thus enabling dynamic, liquid-like behavior (Nott, et. al., 2015; Guo and Shorter, 2015; Elbaum-Garfinkle, et. al., 2015; Molliex, et. al., 2015; Amen and Kaganovich, 2015; Feric, et. al., 2016; Hyman, et. al., 2014; Burke, et. al., 2015). In addition to the presence of low complexity regions, multivalent interactions between complementary binding motifs have been shown to promote LLPS. Recently, Rosen, et al., described one molecular mechanism for the formation of liquid-like droplets as being driven by weak, multivalent protein-protein interactions. Specifically, they found that engineered proteins with multiple SH3 domains phase separate to form liquid-like droplets when mixed with binding partners containing multiple proline-rich motifs (Li, et. al., 2012; Banjade and Rosen, 2014; Su, et. al., 2016). The weak, multivalent interactions were strong enough to form molecular assemblies, but weak enough to maintain the dynamics required for droplet fluidity. Moreover, when valency was increased, the phase separation concentration threshold decreased. In addition to component concentration, $\mathrm{pH}$, salt concentration, temperature, and osmolarity have also been shown to mediate LLPS (Berry, et. al., 2015; Elbaum-Garfinkle, et. al., 2015; Nott, et. al., 2015; Molliex, et. al., 2015; Zhang, et. al., 2015).

\section{The Nucleolus and Ribosome Biogenesis}

Shortly after the introduction of microscopy, roughly in the mid-1800's, biologists observed small, dense bodies in the center of nuclei, which Valentin in 1836 termed the 'nucleolus' (Pederson, 2010). Nucleoli are eukaryotic nuclear membrane-less organelles that are the site for ribosome biogenesis and a sensor of cellular stress (Tafforeau, et. al., 2013). Nucleoli assemble around actively transcribing ribosomal RNA (rRNA) genes (rDNA), termed nucleolar organizing regions (NORs), and are formed through dynamic, but specific, interactions between rRNA, rDNA, and numerous proteins. NORs are found on the short arms of the five acrocentric chromosomes resulting in roughly $600 \mathrm{rDNA}$ repeats per diploid cell and potentially 10 nucleoli per cell (Boisvert, et. al., 2007). Nucleolar formation and disassembly is regulated by the cell cycle in that assembly begins at the beginning of G1 when rDNA transcription is initiated producing fully assembled nucleoli during $\mathrm{S}$ phase; nucleoli begin to disassemble at the beginning of prophase as rDNA transcription machinery becomes phosphorylated leading to termination of transcription and diffusion of proteins out of the outer granular component (GC) region of the nucleolus (Boisvert, et. al., 2007; Hernandez-Verdun, 2011).

Transcription of rDNA occurs at the boundary between the fibrillar center (FC) and the dense fibrillar component (DFC) (Boisvert, et. al., 2007). Successive rRNA splicing and modification occurs in the DFC. Further maturation of pre-rRNA and 


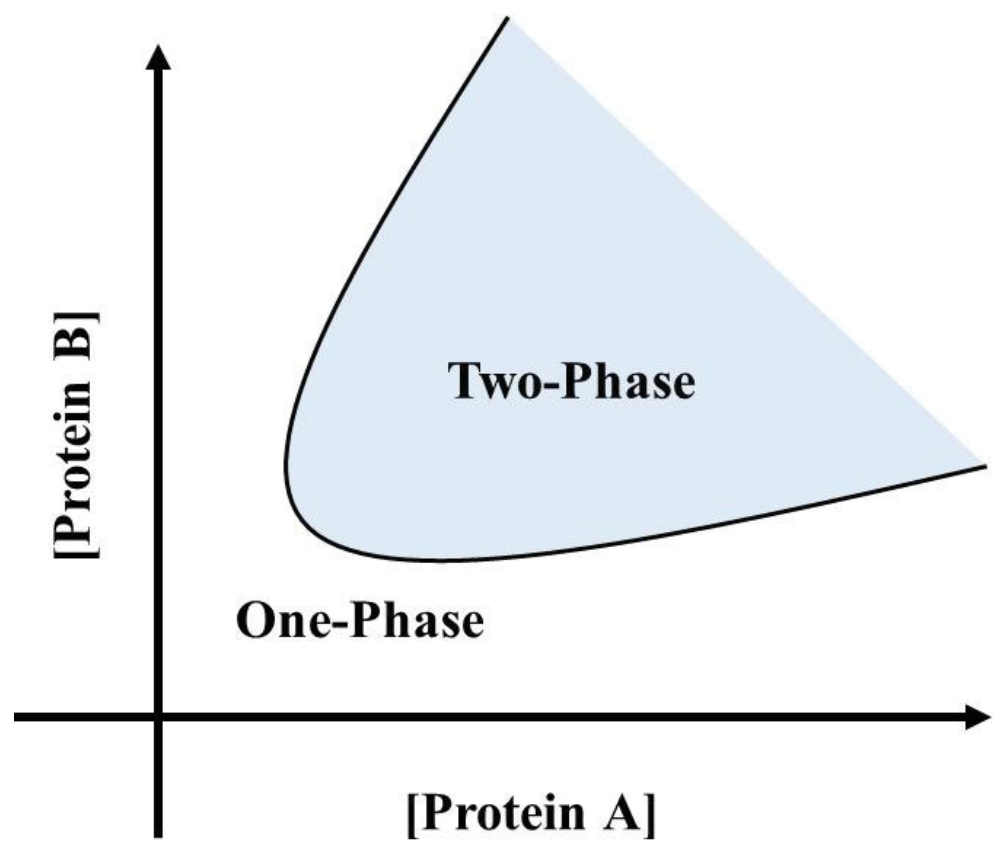

Figure 1-1. Concentration Dependent Phase Diagram 
assembly of pre-ribosomal subunits occurs in the GC (Boisvert, et. al., 2007). The final assembly steps occur in the nucleoplasm and cytoplasm, leading to the formation of complete $80 \mathrm{~S}$ ribosomes. Disrupting ribosome biogenesis and nucleolar stability (e.g., mutations in ribosomal proteins or rRNA processing machinery) has been linked to human diseases including various ribosomopathies, Werner syndrome, RothmundThomson syndrome, and various cancers (Boisvert, et. al., 2007; Montanaro et. al., 2008). For example, mutations within the gene encoding the small subunit ribosomal protein, rpS19, have been shown to disrupt $18 \mathrm{~S}$ rRNA maturation and thus pre-40S subunit production; such alterations in ribosome biogenesis ultimately lead to drastic reduction in erythroid precursor cells, a disease more formally known as Diamond-Blackfan anemia (Boisvert, et. al., 2007). Disrupting nucleolar integrity, either by overexpression or downregulation of nucleolar proteins has also been shown to be involved in the genesis of various cancers (Frye, et. al., 2010; Montanaro, et. al., 2008; Romanova, et. al., 2006). In fact, enlarged nucleoli, most likely due to increased ribosome production, is a hallmark of highly proliferative cells and is commonly used as a phenotypic marker for cancerous cells (Derenzini, et. al., 2009; Montanaro, et. al., 2008). Although the individual processing and maturation steps that are required for ribosome production as well as stress response pathways are known, the molecular basis for nucleolar organization and how this influences the molecular processes within the nucleolus are poorly understood.

Recently, Brangwynne, et al. (2011), demonstrated that nucleoli from Xenopus oocytes exhibit "liquid droplet-like" behavior, including the ability to fuse in vitro. Fibrillar centers were shown to be round but rarely exhibited fusion with other FCs; however, the GC, comprised of rRNA and proteins, underwent fusion and displayed other fluid-like characteristics. Furthermore, it is believed that differences in surface tension between these compartments prevents mixing and thus is responsible for tripartite nucleolar organization (Feric, et. al., 2016). We hypothesize that the liquid-like nature of nucleoli arises from a vast network of multivalent protein-protein and protein-rRNA interactions within the GC. Further, based upon our published and unpublished data, we hypothesize that the nucleolar protein, Nucleophosmin 1 (NPM1), is a central component of this network and is thus critical for the organization of the GC.

\section{Nucleophosmin 1}

Nucleophosmin 1 (NPM1, also referred to as B23, NO3, and numatrin) is a multifunctional protein playing roles in ribosome biogenesis, centrosome duplication, tumor suppression, and as a molecular chaperone and is highly expressed in the nucleolar GC (Grisendi, et. al., 2006; Grisendi, et. al., 2005). NPM1 overexpression is observed in multiple cancers (e.g., gastric, colon, ovarian, and prostate carcinomas) and mutations within the $\mathrm{C}$-terminal nucleic acid binding domain that cause cytoplasmic localization of NPM1 are observed in over 50\% of adult acute myeloid leukemia (AML) cases (E1 Hajj, et. al., 2015; Falini, et. al., 2007; Grisendi, et. al., 2006). Moreover, NPM1 knockout in mice is embryonic lethal, and derived embryonic fibroblasts are viable only when $p 53$ is concomitantly deleted (Grisendi, et. al., 2005). NPM1 exhibits several domains that enable interactions with diverse protein and RNA partners. Specifically, NPM1 contains 
an N-terminal oligomerization domain (termed OD, residues 1-120), a central disordered region, and a $\mathrm{C}$-terminal nucleic acid binding domain (termed CTD, Figure 1-2) (Mitrea, et. al, 2014). An NPM1 monomer exhibits three acidic tracts (A1-A3; A1, residues 34-39; A2, residues 120-132; A3, residues 161-188), which create multivalent acidic patches for binding to other proteins; this multivalency is amplified due to NPM1 pentamerization (Figure 1-3). Recently, using a truncated construct, termed N130 (OD + A2; residues 1130), A1 and A2 were shown to interact with peptides derived from proteins containing disordered regions with multiple arginine-rich motifs (R-motifs); furthermore, binding of an arginine-rich peptide to N130 promoted pentamer formation even with a monomeric phospho-mimetic form of N130, N130 ${ }^{\mathrm{S} 88 \mathrm{E}}$ (Mitrea, et. al., 2014). In addition, the CTD has been shown to bind to various nucleic acid species including rRNA (Wang, et. al., 1994).

Based upon these observations, we propose that multivalent interactions between NPM1's acidic tracts and R-motifs within its nucleolar binding partners contribute to the GC's liquid-like behavior. We further propose that this dynamic behavior can be modulated by changing ionic strength and through incorporation of rRNA into the phase separated network. We first analyzed a list of NPM1 binding partners to identify sequences that we hypothesized would be sufficient for LLPS. Using a minimalistic approach, I next tested if NPM1 could phase separate with R-rich linear motifs using microscopic techniques and, by ITC, found that LLPS was promoted by a network of weak, electrostatic interactions. I then transitioned to using longer protein constructs in order to measure changes in protein dynamics within the droplets in response to the addition of rRNA and changes to valency. Through these experiments, we were able to gain insight into the relationships between molecular features of droplet components and bulk droplet properties (i.e., protein dynamics within droplets). Altogether, through these experiments, we were able to gain an understanding of the types of interactions that are required for in vitro droplet formation by NPM1 with its nucleolar protein and rRNA partners. 


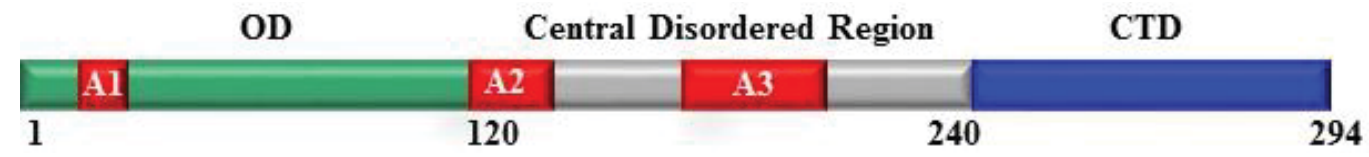

Figure 1-2. Structural Features of Monomeric Nucleophosmin 1

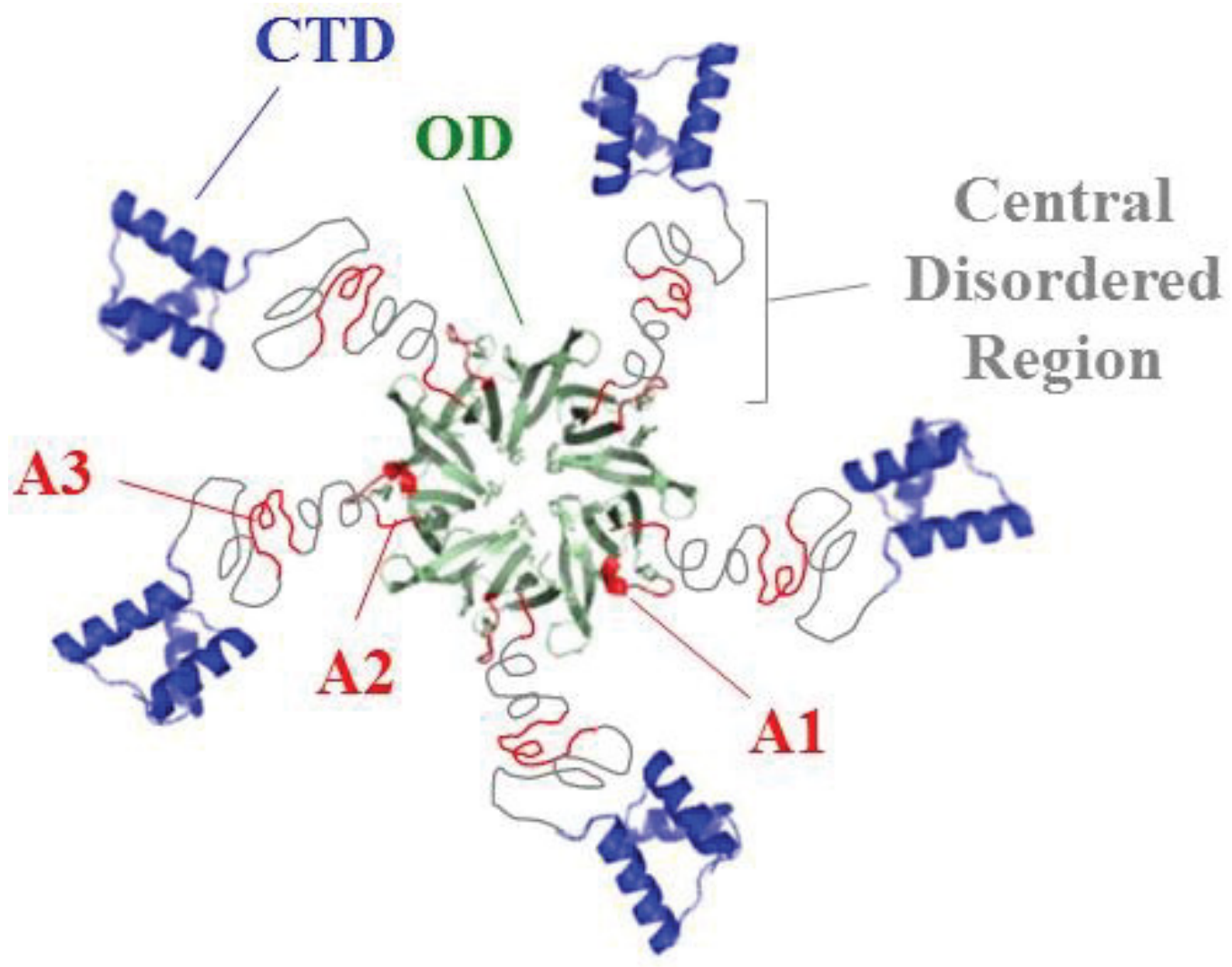

Figure 1-3. Pentameric Structure of Nucleophosmin 1

NPM1 forms a pentamer through its N-terminal oligomerization domain (OD, green; PDB ID 4N8M) and contains a disordered central region (grey), and a folded C-terminal nucleic acid binding domain (CTD, blue; PDB ID 2VXD). NPM1 also harbors three acidic tracts per monomer (A1-A3, red). 


\section{CHAPTER 2. MATERIALS AND METHODS}

\section{Bioinformatics}

A list of 132 NPM1-binding proteins obtained from BioGRID (Huttlin, et. al., 2015) was analyzed using the DAVID Bioinformatics Resources (http://david.abcc.ncifcrf.gov) (Huang da, et. al., 2009) to identify those with known involvement in nucleolar structure and/or function. GO terms were available for 125 of the 132 NPM1-binding proteins (Mitrea, et. al., 2016). Minimal R-motifs were defined as follows: a minimal, single $\mathrm{R}$-motif as the sequence pattern, $\mathrm{RX}_{n 1} \mathrm{R}$, where $\mathrm{n} 1 \leq 2, \mathrm{R}$ is arginine and $\mathrm{X}$ is any amino acid; a minimal, multivalent $\mathrm{R}$-motif as the sequence pattern, $\mathrm{R}_{\mathrm{n} 1} \mathrm{X}_{\mathrm{n} 2} \mathrm{R}_{\mathrm{n} 1} \mathrm{X}_{\mathrm{n} 3} \mathrm{R}_{\mathrm{n} 1} \mathrm{X}_{\mathrm{n} 2} \mathrm{R}_{\mathrm{n} 1}$; where $\left.\mathrm{n} 1>1,0 \leq \mathrm{n} 2 \leq 2,3 \leq \mathrm{n} 3 \leq 20\right)$. A Python algorithm was developed to identify proteins exhibiting multivalent R-motifs and was applied to the list of NPM1-binding proteins as well as a list of 20,193 non-redundant human proteins obtained from the UniProtKB/Swiss-Prot database (http://www.uniprot.org/uniprot/) (UniProt, 2014).

\section{Cloning, Protein Expression, and Purification}

The N130 construct (Appendix A (Figures A-1 to A-4; Table A-1)), cloned into the pET28a vector, was expressed and purified as described previously (Mitrea, et. al., 2014). N294 construct (Table A-1) genes were cloned as previously described (Mitrea, et. al., 2016), however the original PreScission protease cleavage site following the 6xHis tag was replaced with a TEV protease cleavage site. R-protein constructs (Table A-1), derived from their respective human genes, were cloned between NdeI and SalI restriction sites and subcloned into the pET28a vector (Novagen) with a TEV cleavage site following the 6xHis affinity tag. Both N294 and R-proteins, excluding SURF6, were expressed in E. coli strain BL21(DE3) in Luria Broth. The SURF6 protein was expressed in $E$. coli strain Rosetta(DE3) in Luria Broth. The N294 protein expression was induced with $100 \mathrm{mg} / \mathrm{L}$ isopropyl $\beta$-D-1-thiogalactopyranoside (IPTG) (Goldbio) at OD $_{600} \sim 0.6$, and cultures were incubated overnight at $18^{\circ} \mathrm{C}$. Expression of the GNL2 and RPL23a proteins was induced with $100 \mathrm{mg} / \mathrm{L}$ IPTG at $\mathrm{OD}_{600} \sim 0.8$, and cultures were incubated for 3-4 hours at $30{ }^{\circ} \mathrm{C}$. Expression of the SURF6 protein was induced with $100 \mathrm{mg} / \mathrm{L}$ IPTG at $\mathrm{OD}_{600} \sim 0.7$, and cultures were incubated overnight at $18{ }^{\circ} \mathrm{C}$. Bacterial cells were harvested by centrifugation and the proteins were purified as follows.

$\mathrm{N} 294$ cells were lysed by sonication in $10 \mathrm{mM}$ Tris, $300 \mathrm{mM} \mathrm{NaCl}, 10 \mathrm{mM} \beta$ mercapto-ethanol (BME), pH 7.5 supplemented with protease inhibitors (SigmaFAST, Sigma-Aldrich). The soluble fraction of protein was collected by centrifugation and purified by Ni-NTA affinity chromatography. The N294 protein was eluted using $0.5 \mathrm{M}$ imidazole in the buffer and dialyzed overnight against $10 \mathrm{mM}$ Tris, $150 \mathrm{mM} \mathrm{NaCl}, 2 \mathrm{mM}$ dithiothreitol (DTT), $\mathrm{pH} 7.5$ in the presence of TEV protease to cleave the 6xHis-tag. N294 was further purified by HPLC. The lyophilized protein was resuspended in $6 \mathrm{M}$ 
guanidine hydrochloride and refolded by dialyzing against $10 \mathrm{mM}$ Tris, $150 \mathrm{mM} \mathrm{NaCl}, 2$ mM DTT, pH 7.5. Proper protein folding was verified by circular dichroism (CD).

E. coli cells expressing the RPL23a (Figure A-1) protein were lysed by sonication in cold $50 \mathrm{mM}$ sodium phosphate buffer (NaP), $300 \mathrm{mM} \mathrm{NaCl}, 2 \%$ glycerol, pH 8.0 supplemented with protease inhibitors and benzonase endonuclease. The soluble fraction of protein was collected by centrifugation and purified by Ni-NTA affinity chromatography using $0.5 \mathrm{M} \mathrm{NaCl}$ in buffers. RPL23a was eluted using buffer with 0.3 $\mathrm{M}$ imidazole and dialyzed overnight against $10 \mathrm{mM}$ Tris, $300 \mathrm{mM} \mathrm{NaCl}, 2 \mathrm{mM}$ DTT, 2 $\mathrm{mM}$ EDTA, $\mathrm{pH} 8.0$ in the presence of TEV protease to cleave the 6xHis-tag RPL23a was further purified by HPLC. The lyophilized protein was resuspended in $6 \mathrm{M}$ guanidine hydrochloride and refolded by dialyzing against $10 \mathrm{mM}$ Tris, $150 \mathrm{mM} \mathrm{NaCl}, 2 \mathrm{mM}$ DTT, $\mathrm{pH}$ 7.5. Proper protein folding was verified by CD (Appendix B (Figures B-1 to B-2; Table B-1)). Because the nucleolin, GNL2, and SURF6 proteins expressed are disordered, these proteins had to be purified under denaturing conditions.

E. coli cells expressing the Nucleolin (Figure A-2) and GNL2 (Figure A-3) proteins, separately, were lysed by sonication in $100 \mathrm{mM} \mathrm{NaP}, 10 \mathrm{mM}$ Tris, $6 \mathrm{M}$ guanidine $\mathrm{HCl}, \mathrm{pH}$ 8.0. The soluble protein was collected by centrifugation and purified by Ni-NTA affinity chromatography using $25 \mathrm{mM}$ Tris, $500 \mathrm{mM} \mathrm{NaCl}, 20 \mathrm{mM}$ imidazole, $3 \mathrm{M}$ urea, $\mathrm{pH}$ 8.0. The protein was eluted with $0.3 \mathrm{M}$ imidazole in the buffer. The eluted protein was dialyzed overnight against $10 \mathrm{mM}$ Tris, $200 \mathrm{mM} \mathrm{NaCl}, 2 \mathrm{mM}$ DTT, 1 mM EDTA, pH 8.0 in the presence of TEV protease to cleave the 6xHis tag. The cleaved protein was subsequently purified by HPLC, and the lyophilized protein was resuspened in $6 \mathrm{M}$ guanidine $\mathrm{HCl}$ and dialyzed against $10 \mathrm{mM}$ Tris, $500 \mathrm{mM} \mathrm{NaCl}, 2$ $\mathrm{mM}$ DTT, $\mathrm{pH}$ 7.5. Protein disorder was verified by CD (Figure B-2).

E. coli cells expressing the SURF6 (Figure A-4) protein were resuspended in 25 $\mathrm{mM} \mathrm{NaP}, 0.1 \%$ Triton $\mathrm{X}-100$, pelleted by centrifugation, and lysed by sonication in 25 $\mathrm{mM} \mathrm{NaP}, 300 \mathrm{mM} \mathrm{NaCl}, 6 \mathrm{M}$ guanidine $\mathrm{HCl}, 5 \mathrm{mM}$ BME, $\mathrm{pH}$ 7.0. Soluble protein was collected by centrifugation and purified by Ni-NTA affinity chromatography using $0.5 \mathrm{M}$ $\mathrm{NaCl}$ in buffers. Protein was eluted with $0.5 \mathrm{M}$ imidazole containing buffers and dialyzed overnight against $10 \mathrm{mM} \mathrm{NaP}, 150 \mathrm{mM} \mathrm{NaCl}, 2 \mathrm{mM}$ DTT, pH 7.0 in the presence of TEV protease to cleave the 6xHis tag. Likewise, SURF6 was further purified by HPLC and the lyophilized protein was resuspened in $6 \mathrm{M}$ guanidine $\mathrm{HCl}$ and dialyzed against 10 $\mathrm{mM}$ Tris, $500 \mathrm{mM} \mathrm{NaCl}, 2 \mathrm{mM}$ DTT, $\mathrm{pH}$ 7.5. Protein disorder was verified by CD (Figure B-2).

The N130 construct was chemically labeled with Alexa Fluor488 $\mathrm{C}_{5}$ maleimide (Life Technologies) as previously described (Mitrea, et. al., 2016). Similarly, N294 was labeled with Alexa Fluor488 $\mathrm{C}_{5}$ maleimide (Life Technologies) following the manufacturer's protocol. To ensure selective labeling at the solvent exposed Cys104, Cys21 and Cys275 were mutated to a threonine. Labeling was carried out in $10 \mathrm{mM}$ Tris, $150 \mathrm{mM} \mathrm{NaCl}, \mathrm{pH}$ 7.5. Excess dye was removed by dialysis. The N-termini of GNL2 and SURF6 were chemically labeled with Alexa Fluor555 NHS-ester (Life Technologies) according to the manufacturer's protocol. Prior to labeling, the proteins were dialyzed 
against $20 \mathrm{mM} \mathrm{NaP}, 500 \mathrm{mM} \mathrm{NaCl}, 2 \mathrm{mM}$ DTT, pH 7.0. Labeling was carried out in the same buffer. Excess dye was removed by dialysis.

\section{Peptide Synthesis}

Peptides used for ITC and LLPS screening assays were synthesized by the Macromolecular Synthesis resource within St. Jude Children's Research Hospital's Hartwell Center for Bioinformatics and Biotechnology.

\section{Determination of Protein, Peptide, and RNA Concentrations}

Protein concentrations were calculated in denaturing conditions using a $1 \mathrm{~mm}$ cuvette to measure their absorbance at $280 \mathrm{~nm}$ and their respective extinction coefficient (Table B-1). Lyophilized peptides were dissolved in $10 \mathrm{mM}$ Tris, $150 \mathrm{mM} \mathrm{NaCl}, \mathrm{pH} 7.5$ and concentrations were calculated using the same method as proteins. RNA concentrations were calculated using the nucleic acid setting on a NanoDrop 2000c UVVis Spectrophotometer (Thermo Scientific).

\section{Isothermal Titration Calorimetry}

Titrations were performed using an Auto-iTC200 instrument (formerly GE Healthcare, now Malvern), at $25^{\circ} \mathrm{C}$, with N130 or N122 in the cell. Lyophilized peptides were dissolved in $10 \mathrm{mM} \mathrm{NaP}, 150 \mathrm{mM} \mathrm{NaCl}, 2 \mathrm{mM}$ DTT, pH 7.0 and dialyzed overnight against the fresh $\mathrm{NaP}$ buffer to eliminate residual TFA. Protein and peptide concentrations were selected to be below the phase separation threshold to prevent LLPS during the experiments. Data was analyzed using Origin Software to obtain stoichiometries $(n)$, enthalpies of binding $(\Delta H)$ and dissociation constants $\left(K_{d}\right)$.

\section{Turbidity Measurements}

Proteins and peptides or peptides and wheat germ rRNA (bioPLUS) were mixed to a final volume of $10 \mu \mathrm{l}$. Samples were incubated for 5 minutes at room temperature prior to analysis. Absorbance at $340 \mathrm{~nm}$ for $3 \mu \mathrm{L}$ samples was measured on a NanoDrop 2000c UV-Vis Spectrophotometer (Thermo Scientific). Measurements were performed in triplicate.

\section{Slide Coating for Microscopy}

CultureWell 16-well chambered cover glass slides (Grace BioLabs) were washed with detergent and ethanol and dried prior to being treated with PlusOne Repel-Silane ES

(GE Healthcare). Slides were subsequently washed with ethanol and water, dried, and 
coated with 1\% PF-127 (Sigma). Slides were covered and left overnight at room temperature. PF-127 solution was removed and slides were dried immediately prior to use.

\section{Fluorescence Microscopy}

Initially, wide field microscopy DIC and $488 \mathrm{~nm}$ fluorescent images were collected to screen for droplet formation and map phase diagrams with N130 and peptides on a Nikon C1Si microscope with a 60x magnification oil objective (Nikon Instruments). $10 \mu 1$ samples, spiked with $1 \mu \mathrm{M}$ Alexa Fluor488-N130, were incubated at room temperature for 5 minutes prior to analysis. Droplets were defined as having an area greater than 9 squared pixels $(0.2 \mu \mathrm{m} /$ pixel $)$ and circularity of $0.5-1$, which were measured using ImageJ. Particles smaller than 9 squared pixels were visible by fluorescence but not DIC at low protein and peptide concentrations; however, these objects were below the threshold to confidently measure circularity. Therefore droplet formation was not recorded until particles could be observed by DIC. DIC and $488 \mathrm{~nm}$ fluorescent images of droplets using different peptide linker lengths were acquired by confocal microscopy on the same instrument and with the same objective. For droplets with longer constructs, $75 \mu \mathrm{L}$ samples, spiked with $1 \mu \mathrm{M}$ Alexa Fluor488-N294 and 2 $\mu \mathrm{M}$ Alexa Fluor555-Surf6 or $5 \mu \mathrm{M}$ Alexa Fluor555-GNL2, were incubated at room temperature in chamber well slides for $30 \mathrm{~min}$ to allow droplets to form and fuse with one another prior to analysis. $488 \mathrm{~nm}$ and $561 \mathrm{~nm}$ fluorescent images were acquired on a Zeiss Axio Observer microscope (Carl Zeiss Microscopy) equipped with CSU-X spinning disk confocal heads (Yokagawa) using a 100x magnification objective with oil. Images were analyzed using SlideBook software.

\section{Fluorescence Recovery after Photobleaching}

Fluorescence recovery after photobleaching (FRAP) experiments were performed on the same equipment as described above for SURF6, GNL2, RPL23a, and Nucleolin. A circular area of $\sim 1 \mu \mathrm{m}$ in diameter at the center of droplets was photobleached using a $488 \mathrm{~nm}$ laser for Alexa488-labeled N294 at 100\% power and recovery was monitored, for 3 minutes or until recovery plateaued, at $0 \mathrm{~ms}$ intervals between points. Similarly, in separate droplets, $\sim 1 \mu \mathrm{m}$ in diameter areas were photobleached with a $561 \mathrm{~nm}$ laser for Alexa561-labeled SURF6 or GNL2. FRAP data was normalized to the background fluorescence (Equation 1-1) where $\mathrm{F}_{\mathrm{ROI}}$ is the fluorescence intensity inside the bleached region at times $t$ after photobleaching, and $\mathrm{F}_{0}$ is the ROI fluorescence intensity before photobleaching. $F_{\text {background }}$ is the fluorescence intensity at times $t$ of an area outside of a droplet.

$$
F(t)=\frac{F_{R O I}-F_{\text {background }}}{F_{0}-F_{\text {background }}}
$$

N294/GNL2 recovery curves were best fit to a nonlinear regression curve (Equation 1-2) where $F_{0}$ and $F_{\infty}$ are the fluorescent intensities of the bleached region 
immediately following photobleaching and at full recovery, respectively, and $t_{1 / 2}$ is the half-time of recovery.

$$
F(t)=\frac{F_{0}+F_{\infty} \frac{t}{t_{1 / 2}}}{1+\frac{t}{t_{1 / 2}}}
$$

N294/SURF6 curves were best fit to a single exponential (Equation 1-3), where $\mathrm{A}$ is the maximum fluorescence recovery and directly correlates to the mobile fraction of protein and $\tau$ is the recovery timescale.

$$
F(t)=A\left(1-\mathrm{e}^{-\mathrm{t}^{*} \tau}\right)
$$

The rate of diffusion can then be estimated using the half-time of recovery, $\mathrm{t}_{1 / 2}$, or the recovery timescale, $\tau$, and the bleached radius, $w$ (Equation 1-4 and Equation 1-5) (Elbaum-Garfinkle, et. al., 2015; Kang et. al., 2012).

$$
\begin{gathered}
D=\frac{w^{2}}{\tau} \\
D=\frac{w^{2}}{4 t_{1 / 2}}
\end{gathered}
$$

Normalized FRAP curve fitting and diffusion plots were generated using KaleidaGraph software. P values were calculated using the GraphPad t test calculator freely available online (http://www.graphpad.com/quickcalcs/). 


\section{CHAPTER 3. RESULTS}

\section{Characterizing Features of NPM1 Binding Partners}

We first sought to determine if R-motifs were a common feature of NPM1 binding partners. To gain insight into the molecular basis for interactions with NPM1, we determined the occurrence of multivalent R-motifs within the sequences of the 132 NPM1-binding proteins, identified in HEK293T cells by affinity mass spectrometry (Huttlin, et. al., 2015). We found that over $73 \%$ of these proteins exhibited at least one multivalent R-motif; in contrast, only $44 \%$ of all human proteins exhibited a multivalent R-motif (Mitrea, et. al., 2016). These data show that NPM1 binding partners are enriched in multivalent R motifs, when compared to the human proteome $(\mathrm{p}<0.0001)$. Furthermore, analysis of Gene Ontology terms indicated that over $50 \%$ of the NPM1 binding partners were nucleolar proteins (Mitrea, et. al., 2016). Using the protein disorder predictor, IUPred, we found that most of the proteins are predicted to be completely disordered or contain disordered regions which harbor most, if not all, of the multivalent R-motifs (Supplemental Data for Chapter 3).

Next, we analyzed a library of R-motif containing peptides (R-peptides), derived from nucleolar proteins identified above (Table 3-1), to confirm binding to NPM1 and to measure binding affinities. As we wanted to maintain a minimalistic system, we used an NPM1 construct capable of forming a pentamer which contained acidic tracts A1 and A2 (termed N130) and a construct with only A1 (termed N122). The synthetic R-peptides were made to only include the multivalent R-motif. An additional RPL5 ${ }^{21-37}$ peptide was constructed, termed RPL5-RA, in which the second R-motif (RKR) was changed to AKA in order to test the importance of multivalency on binding stoichiometry and affinity. We then used isothermal titration calorimetry (ITC) to confirm binding, measure equilibrium dissociation constants, and calculate binding stoichiometry. We observed differences in binding affinity and capacity for each of the peptides binding to N122 and N130 (Figure 3-1 and Table 3-2). RPL23a $\mathrm{a}^{47-68}$ has three possible R-motifs that could potentially interact with NPM1, with different affinities; the ITC curve produced from RPL23a and N130 exhibited multimodal binding and therefore could not be fit using the standard binding models available in the manufacturer's Origin software. Multiple binding events were also observed with GNL2 ${ }^{682-709}$ and N130. With N122, RPL5-RA bound at roughly 1:1 stoichiometry, whereas the other peptides exhibited $\mathrm{N}$ values below one, indicative of either peptide aggregation or multiple N122 monomers per peptide. The presence of two R-motifs increased binding affinity as the RPL5-RA bound to N122 and N130 at much lower affinities than the other peptides, $61.4 \mu \mathrm{M}$ (RPL5-RA) versus 10-20 $\mu \mathrm{M}$ (other peptides) for N122 and $89 \mu \mathrm{M}$ (RPL5-RA) versus roughly $20 \mu \mathrm{M}$ (other peptides) for N130. Furthermore, binding capacity was increased from $\mathrm{N}=1$ to $\mathrm{N}=2$ for peptides containing more than one R-motif when an additional acidic tract was present (i.e., with N130).

We were able to show that R-rich motifs are common sequence features of NPM1 binding partners and that peptides containing these motifs were able to bind to the N- 
Table 3-1. Synthetic Peptides of NPM1 Binding Partners

\begin{tabular}{ll}
\hline Peptide & Sequence \\
\hline RPL23a $^{47-68}$ & RRPKTLRLRRQPKYRKSAPRR \\
GNL2 $^{682-709}$ & RRRAVRQQRPKKVGVRYYEHNVKNRNR \\
SURF6 $6^{29-326}$ & RRAQRQRRWEKRTAGVVEKMQQRQDRRR \\
RPL551-37 & RRRREGKTDYYARKRLV \\
RPL5-RA & RRRREGKTDYYAAKALV \\
RPL5-20L & RRRRGSGSGSGSGYYSGSGSGSGSRKRLV \\
RPL5-16L & RRRRGSGSGSGYYSGSGSGSRKRLV \\
\hline
\end{tabular}



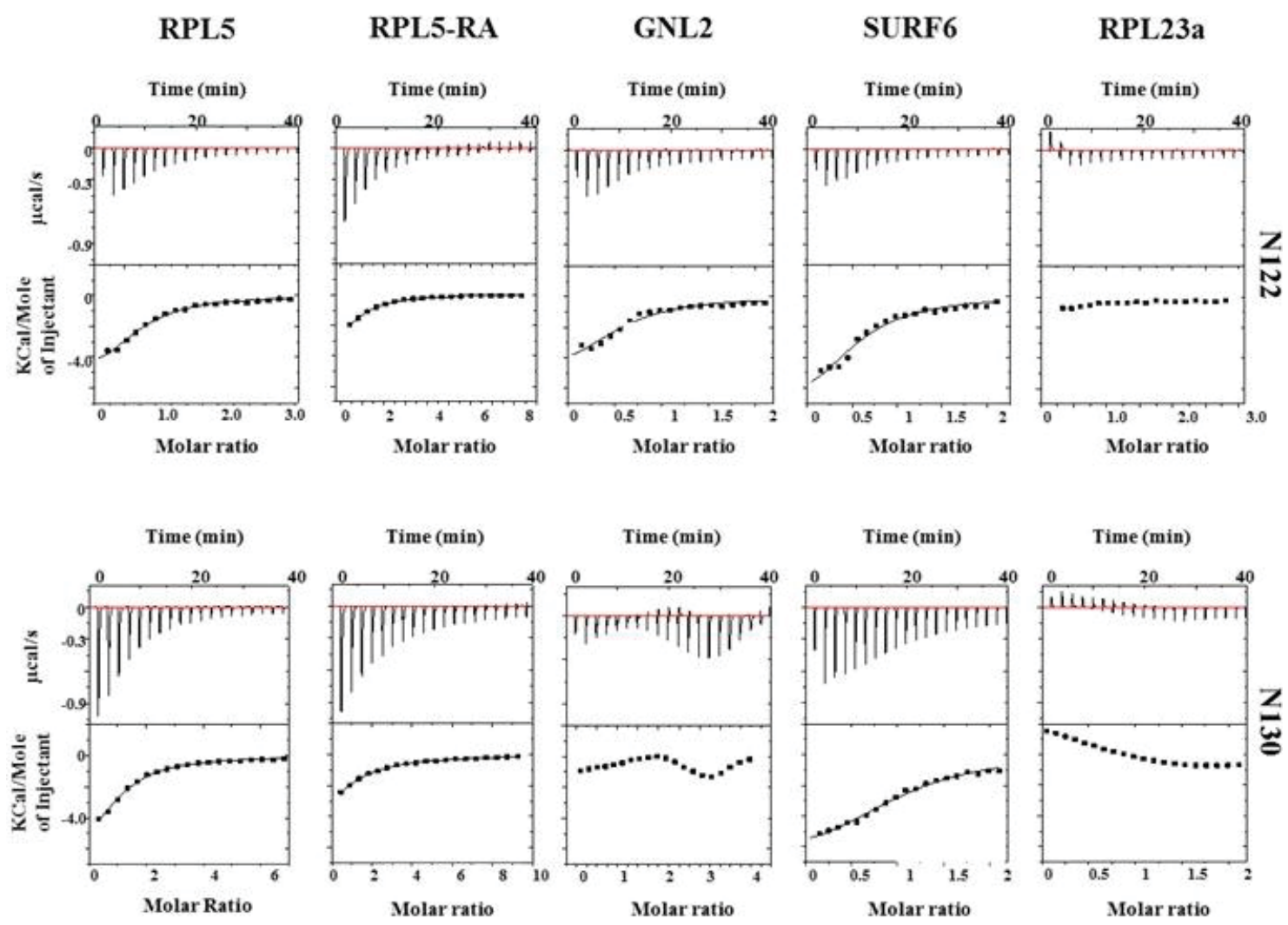

Figure 3-1. ITC Curves for NPM1 with R-Peptides

Respective ITC curves for R-peptide titrations into N122 (top) and N130 (bottom).

Concentrations were kept below the phase separation threshold. The curves represent one of the three titrations for each peptide.

Reprinted with permission from: Mitrea, D. M., Cika, J. C., Guy, C. S., Ban, D., Banerjee, P. R., Stanley, C. B., Nourse, A., Deniz, A. A., Kriwacki, R. W. (2016).

Nucleophosmin integrates within the nucleolus via multi-modal interactions with proteins displaying R-rich linear motifs and rRNA. eLife, 5. 
Table 3-2. ITC Data for NPM1 with R-Peptides

\begin{tabular}{|c|c|c|c|c|}
\hline \multirow[b]{2}{*}{ Peptide } & \multicolumn{2}{|c|}{ N122 } & \multicolumn{2}{|c|}{ N130 } \\
\hline & $\mathbf{N}$ (sites) & $K_{D}(\mu M)$ & N (sites) & $K_{D}(\mu M)$ \\
\hline RPL23a $a^{47-68}$ & n.d. ${ }^{\#}$ & n.d. ${ }^{\#}$ & n.d. & n.d. \\
\hline GNL2 ${ }^{682-709}$ & $0.66 \pm 0.04$ & $10.2 \pm 1.3$ & n.d. ${ }^{*}$ & n.d. ${ }^{*}$ \\
\hline SURF6 $^{299-326}$ & $0.55 \pm 0.06$ & $9.2 \pm 0.5$ & $1.4 \pm 0.02$ & $19.0 \pm 0.8$ \\
\hline RPL5 $^{21-37}$ & $0.63 \pm 0.09$ & $19.0 \pm 2.7$ & $2.2 \pm 0.19$ & $20.5 \pm 5.0$ \\
\hline RPL5-RA & $1.18 \pm 0.06$ & $61.4 \pm 0.5$ & $1.2 \pm 0.07$ & $88.9 \pm 0.3$ \\
\hline
\end{tabular}

*Not determined due to multiple, unresolved binding events. "Heat change was too weak for accurate data analysis. Data was averaged from a minimum of three independent experiments $\pm \mathrm{SD}$.

Reprinted with permission from: Mitrea, D. M., Cika, J. C., Guy, C. S., Ban, D., Banerjee, P. R., Stanley, C. B., Nourse, A., Deniz, A. A., Kriwacki, R. W. (2016). Nucleophosmin integrates within the nucleolus via multi-modal interactions with proteins displaying R-rich linear motifs and rRNA. eLife, 5. 
terminal oligomerization domain and a portion of the central disordered region, presumably via A1 and A2 (Mitrea et. al., 2014), with $\mu \mathrm{M} \mathrm{K}_{\mathrm{d}}$ values. Next we wanted to test whether these multivalent R-motifs were sufficient for phase separation into liquidlike droplets with NPM1.

\section{Survey for Droplet Formation with NPM1 and Peptides}

Based on published work on membrane-less organelles and phase separation (Brangwynne et. al., 2011; Li et. al., 2012), we hypothesized that multivalent interactions between NPM1 and the identified R-motif-containing nucleolar proteins and rRNA contribute to the liquid-like nucleolar environment and would promote droplet formation in vitro. We started with a minimalistic system analyzing only multivalent $\mathrm{R}$-motif peptides and N130 as was done with ITC experiments discussed above. Using a fluorescently labeled N130 construct (A488-N130) we analyzed for droplet formation by microscopy at various concentrations in order to map a phase diagram for each peptide. In support of our hypothesis, each of the peptides underwent LLPS with N130 (Figure 3-2). Next we tested how the length of the linker between R-motifs within a multivalent R-motif peptide alters droplets morphology. For this, we used a synthetic RPL5 peptide with the residues between the R-motifs altered to include varying lengths of glycineserine (GS) repeats (RPL5-20L with a 20 residue-long linker and RPL5-16L with a 16 residue-long linker; Table 3-1). N130 and the peptides were mixed under conditions associated with LLPS by the wild type RPL5 peptide (1:3 N130:RPL5 peptide molar ratio, $200 \mu \mathrm{M}$ N130). As was observed with the wild type RPL5 peptide, these divalent peptides phase separated with N130 to form liquid-like droplets; furthermore, larger droplets were observed as the linker length was increased (Figure 3-3). To confirm that divalency of R-motifs was required for LLPS, we tested whether the monovalent RPL5 peptide, RPL5-RA (Table 3-1) underwent phase separation with N130; as expected, LLPS was not observed (Mitrea, et. al., 2016). Finally, we addressed the requirement for multivalency of acidic tracts within N130 for LLPS with bivalent R-motif peptides by performing experiments with N122, which lacks the A2 acidic tracts. N122 was mixed with RPL5 and RPL5-R2A peptides and turbidity was measured to monitor phase separation. N122 did not undergo LLPS with any of the peptides, showing that bivalency of acidic tracts within a N130 subunit is required for phase separation (Mitrea et. al., 2016). These data have shown that R-motifs bind to NPM1 acidic tracts, A1 and A2, via weak, electrostatic interactions, and that phase separation requires a highly multivalent system.

As rRNA is a major nucleolar component, we next tested if the R-peptides could also undergo LLPS with wheat germ rRNA. Using various concentrations of rRNA and R-peptides, we measured turbidity of the solution as an indication of phase separation. Indeed, each of the peptides underwent phase separation with rRNA; however, when these solutions were analyzed by differential interference contrast (DIC) microscopy, we observed small puncta ( $\sim 1 \mu \mathrm{m}$ in diameter) rather than droplets (Figure 3-4). 


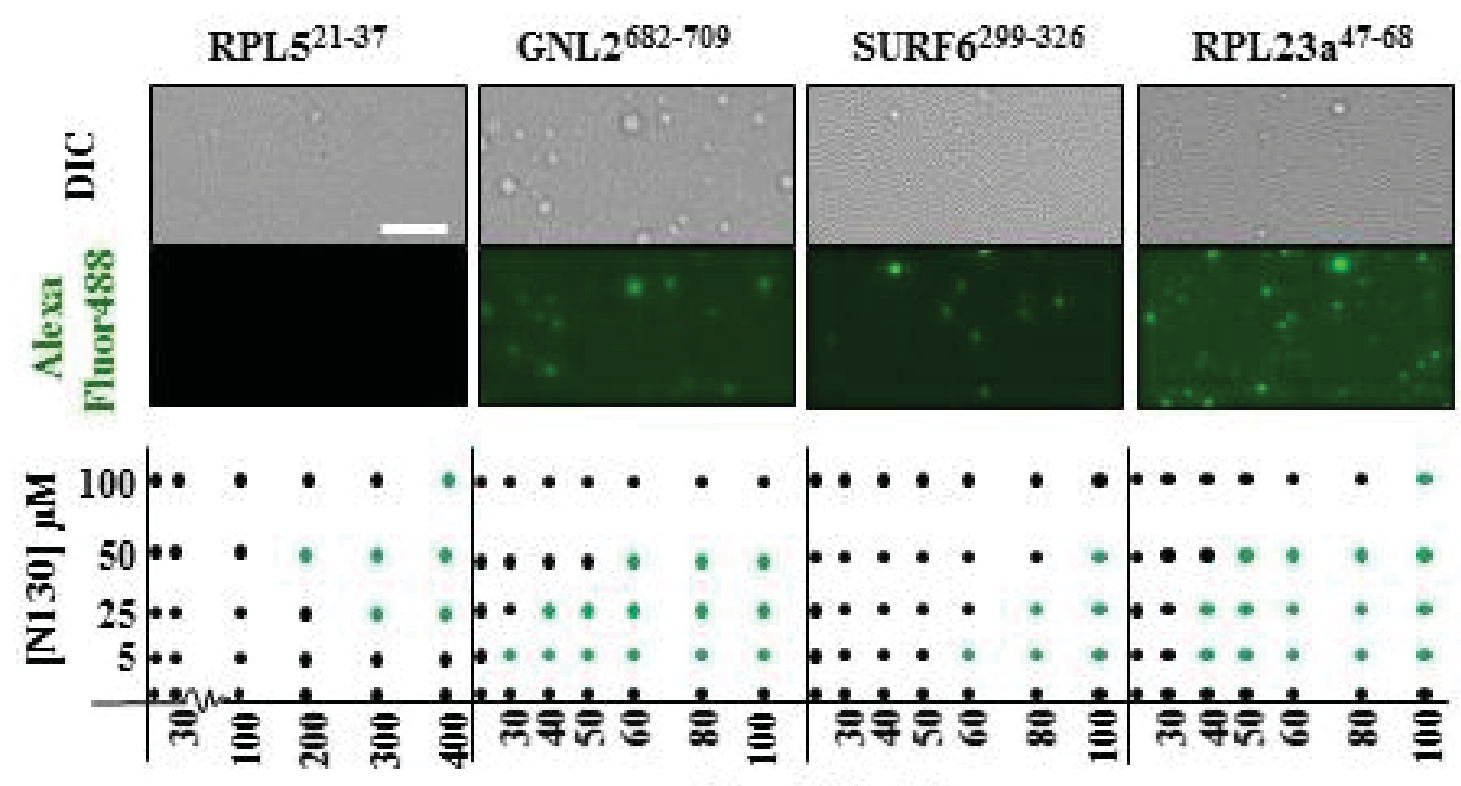

[Peptide] $\mu \mathrm{M}$

Figure 3-2. N130 Phase Separates with a Variety of R-Motifs Containing Peptides Phase diagrams for each of the multivalent R-motif peptides analyzed. Peptides were titrated into N130 (spiked with $1 \mu \mathrm{M}$ Alexa Fluor488) and imaged by wide field microscopy. Images, DIC (top) and Alexa Fluor488 N130 emission (bottom) shown are at $50 \mu \mathrm{M} \mathrm{N} 130$ and the lowest peptide concentration where droplet formation was observed. Scale bar: $5 \mu \mathrm{m}$

Reprinted with permission from: Mitrea, D. M., Cika, J. C., Guy, C. S., Ban, D., Banerjee, P. R., Stanley, C. B., Nourse, A., Deniz, A. A., Kriwacki, R. W. (2016). Nucleophosmin integrates within the nucleolus via multi-modal interactions with proteins displaying R-rich linear motifs and rRNA. eLife, 5. 

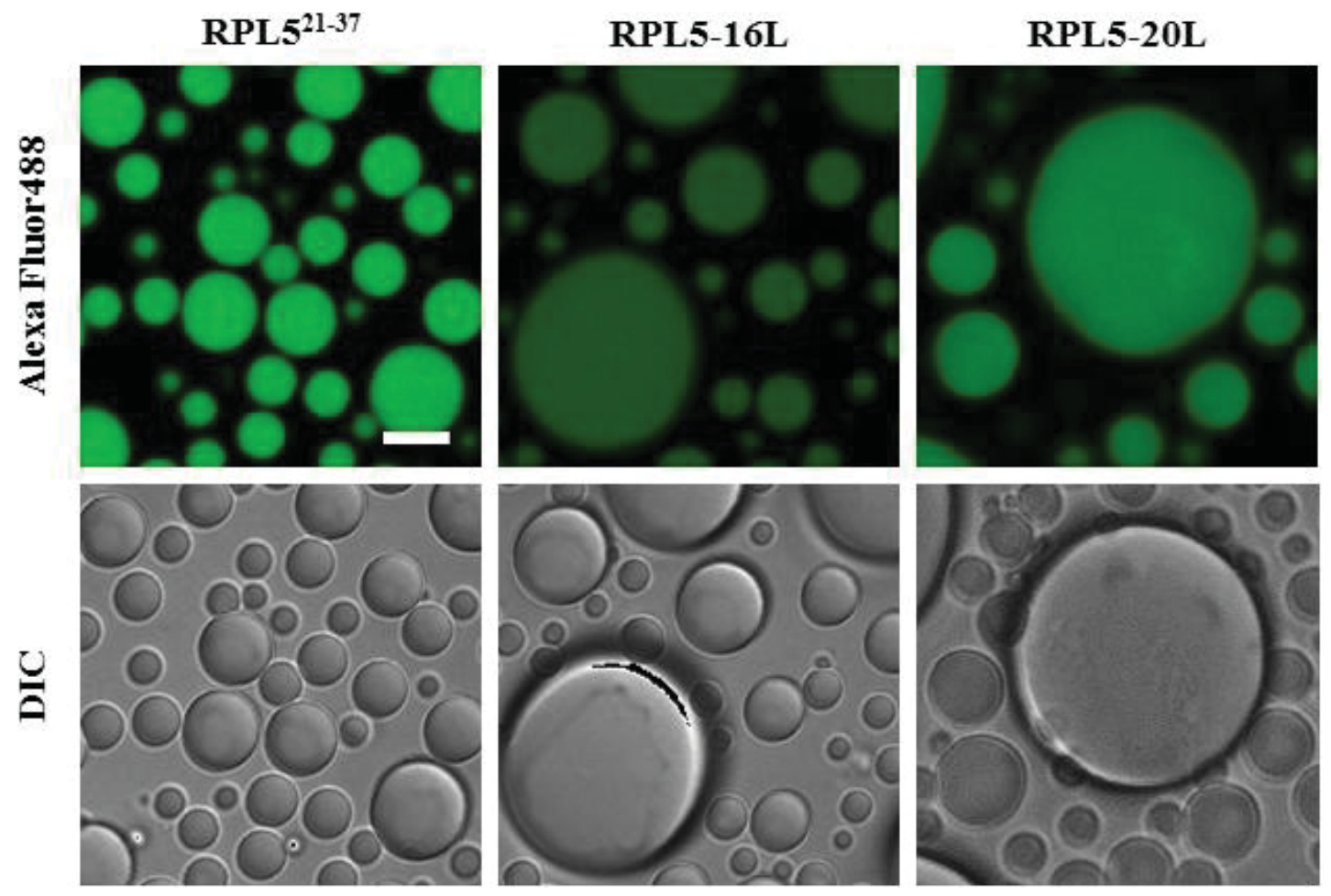

Figure 3-3. Linker Length Dictates N130 Droplet Size

Confocal images, DIC (bottom) and Alexa Fluor488 N130 emission (top) shown are at $200 \mu \mathrm{M}$ N130 (including $2 \mu \mathrm{M}$ Alexa Fluor488 N130) and $600 \mu \mathrm{M}$ peptide. Droplets were imaged 1 hour after mixing. Scale bar: $10 \mu \mathrm{m}$. 
A.

rRNA into $50 \mu \mathrm{M}$ Peptide

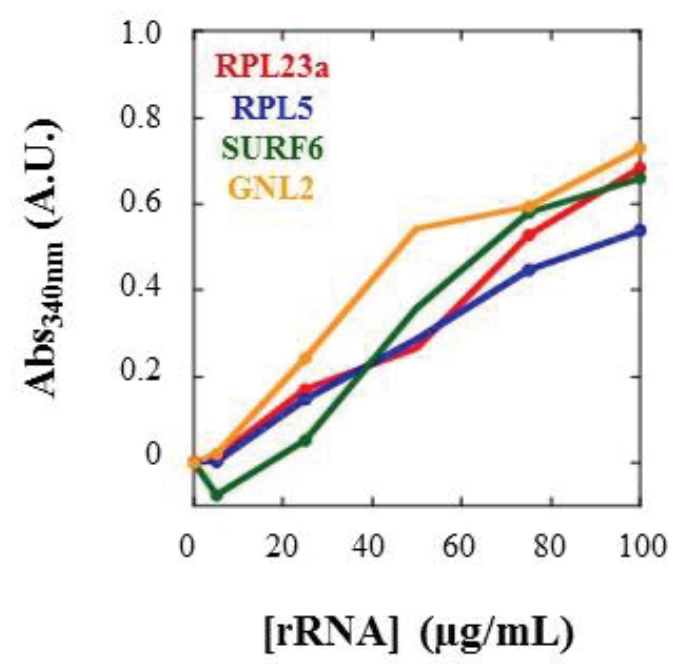

C.

RPL23a

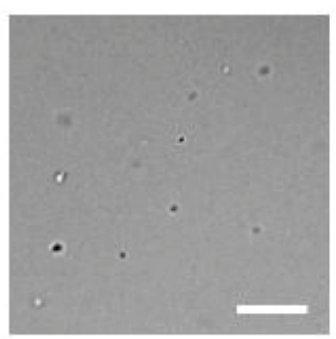

B.

Peptide into $50 \mu \mathrm{g} / \mathrm{mL}$ rRNA

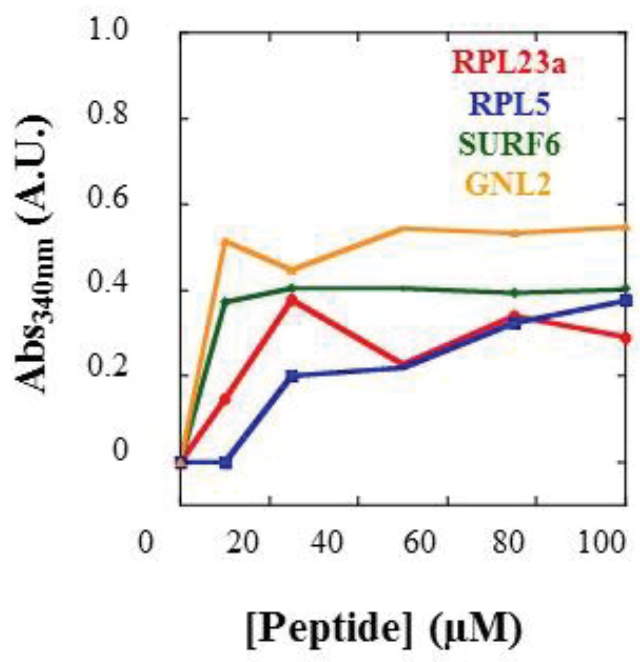

SURF6

GNL2

Figure 3-4. Phase Separation of R-Peptides with rRNA by Turbidity

Absorbance measured at $340 \mathrm{~nm} 5$ minutes after mixing. A. Titrations of wheat germ rRNA into each $50 \mu \mathrm{M}$ peptide. B. Titrations of each peptide into $50 \mu \mathrm{g} / \mathrm{mL}$ wheat germ rRNA. C. DIC images of $25 \mu \mathrm{M}$ R-peptide into $50 \mu \mathrm{g} / \mathrm{mL}$ rRNA. Scale bar: $10 \mu \mathrm{m}$.

Reprinted with permission from: Mitrea, D. M., Cika, J. C., Guy, C. S., Ban, D., Banerjee, P. R., Stanley, C. B., Nourse, A., Deniz, A. A., Kriwacki, R. W. (2016).

Nucleophosmin integrates within the nucleolus via multi-modal interactions with proteins displaying R-rich linear motifs and rRNA. eLife, 5. 


\section{Survey for Droplet Formation with Longer Constructs and rRNA}

We next extended our studies to address the role of R-motifs within full-length proteins, or long protein segments, in interactions with full-length NPM1, as well as its interactions of rRNA (Figure 3-5a). We prepared constructs for proteins from which three of our R-peptides (SURF6 ${ }^{1-182}$, GNL2 $2^{630-731}$, and RPL23 $a^{1-156}$ ) were derived and for an additional nucleolar protein, Nucleolin ${ }^{610-709}$. Each of these constructs are predicted to be disordered or contain disordered regions containing the multivalent R-motifs (Figure 3-5a). Due to problems purifying the full-length SURF6 (360 residues) protein, we used a construct with the first 182 residues which contains six R-motifs. Full-length RPL23a was able to be purified and was used in the following experiments. As GNL2 and Nucleolin are much larger proteins (over 700 residues) we made constructs corresponding to their C-terminal disordered regions which contained the multivalent $\mathrm{R}$ motifs that were predicted to interact with NPM1 and promote phase separation. In addition to studying these longer R-protein constructs, we also began studying full-length NPM1 (N294), which contains an additional acidic tract (A3) and the C-terminal nucleic acid binding domain (CTD), rather than N130.

The various R-proteins were mixed with NPM1 and confocal microscopy was used to monitor phase separation into liquid-like droplets. For these experiments, a small amount of fluorescently-labeled mutant NPM1 (Cys 21 and Cys 275 mutated to Thr) was mixed with an excess of wild-type NPM1. As we observed with R-motif containing peptides, each of the R-proteins were able to phase separate with N294, however not all R-proteins formed liquid-like droplets. Specifically, SURF6/N294 and RPL23a /N294 formed droplets which fused, GNL2/N294 formed non-fusing droplets, and nucleolin/NPM1 did not form droplets, but rather phase separated into a solid-like state (Figure 3-5b). Using the same microscopic approach, we next tested if NPM1 could phase separate with the same wheat germ rRNA as used with the peptides, as NPM1 harbors the CTD that binds nucleic acids. Indeed, NPM1 and rRNA phase separated to form liquid-like droplets (Figure 3-6a); furthermore, nucleolin, which did not form liquid-like droplets with N294, became incorporated into N294/rRNA droplets (Figure 3-6b). To test if NPM1 is required for R-proteins to undergo LLPS with rRNA, we used our longest R-protein construct with the most R-motifs, SURF6 and, using confocal microscopy, monitored droplet formation with $100 \mu \mathrm{g} / \mathrm{mL}$ rRNA. Unlike the R-peptides, SURF6 formed liquid-like droplets with only rRNA; imaging the droplets 18 hours later, we observed that these droplets remain smaller overtime than N294/SURF6 and N294/SURF6/rRNA droplets (Figure 3-6c). Furthermore, droplets formed in the absence of rRNA appeared larger than those formed with rRNA.

\section{Measuring Protein Dynamics within NPM1 and Arginine-Rich Nucleolar Protein Droplets}

After establishing that NPM1 phase separated with a variety of nucleolar binding partners, R-proteins and rRNA, we next sought to determine how modulating the 
A.

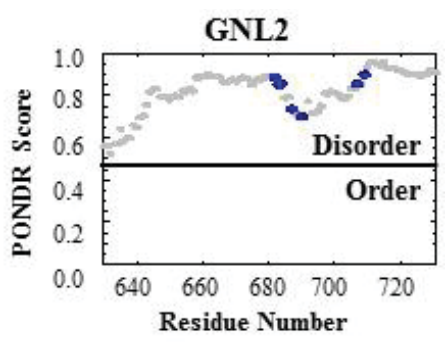

GNL2
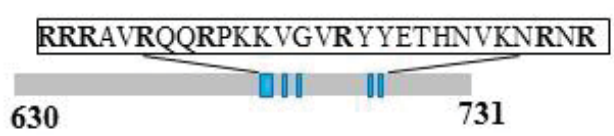

31
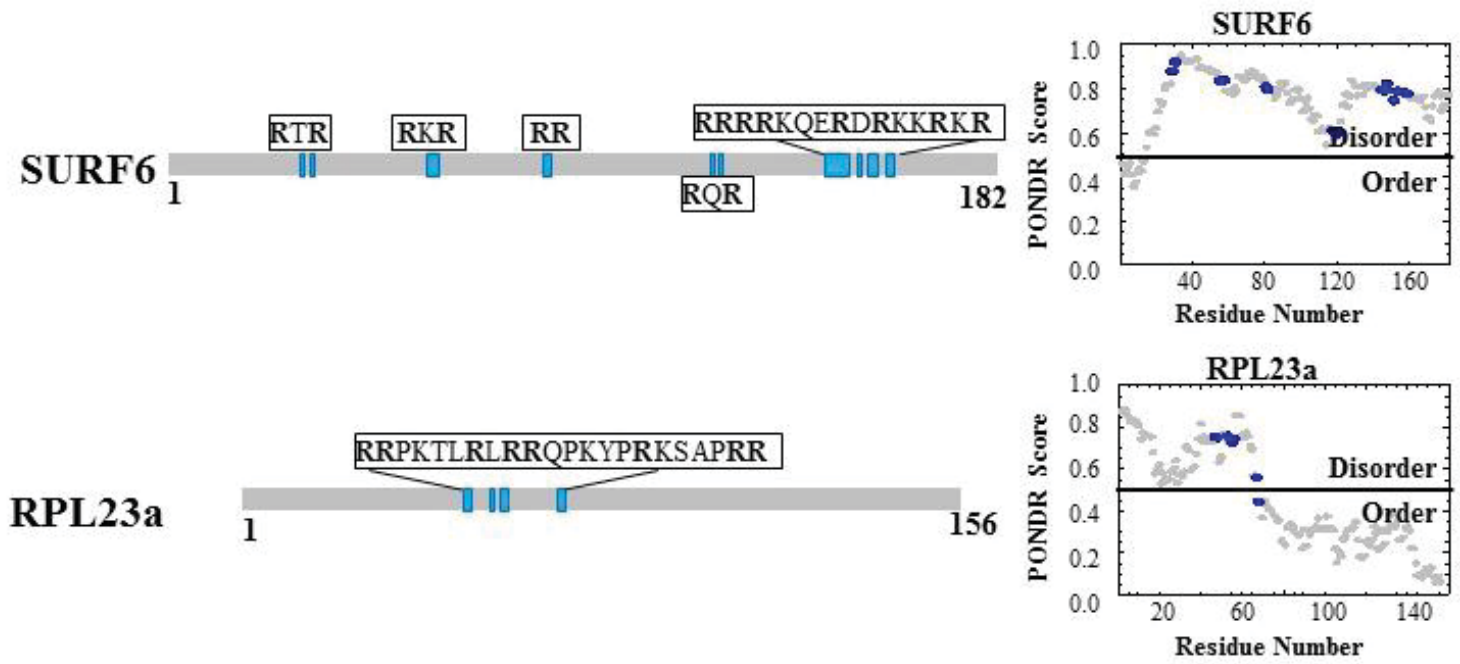

\section{RGGRGGFGGRGRGGFGGRGGFRGGR}

Nucleolin

610

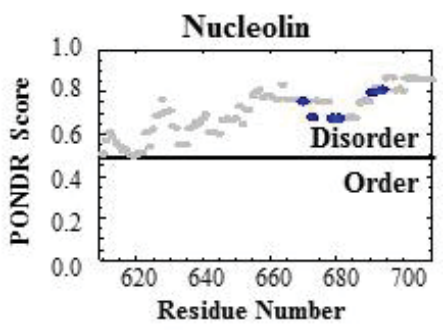

B.
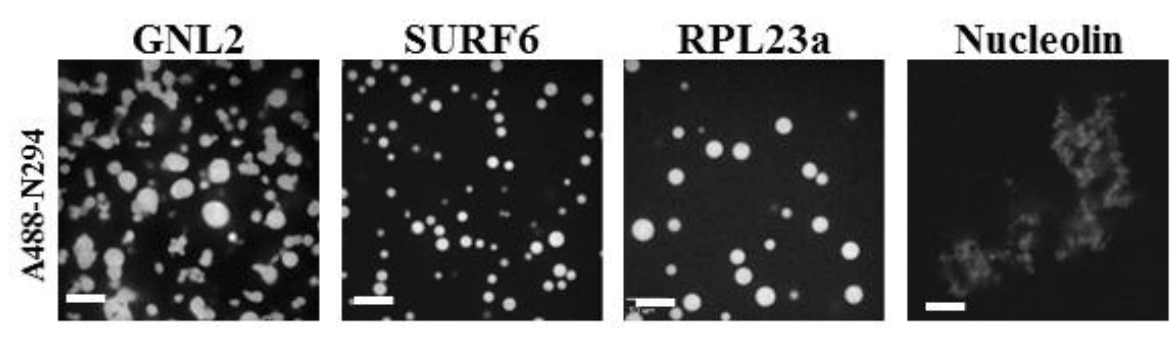

Figure 3-5. N294 Phase Separates with a Variety of R-Proteins

A. Schematics of the studied R-proteins with R-motifs highlighted in blue. PONDR disorder prediction plots correspond to the truncated protein. R-motifs are highlighted in blue. B. $10 \mu \mathrm{M}$ N294 with $20 \mu \mathrm{M}$ R-proteins, spiked with $1 \mu \mathrm{M}$ A488-N294. Scale bar: $10 \mu \mathrm{m}$ 
A.

N294 + rRNA

Alexa Fluor 488

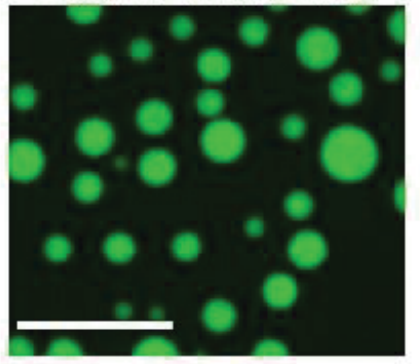

C.

$\underline{30 \mathrm{~min}}$

18 hrs
B.
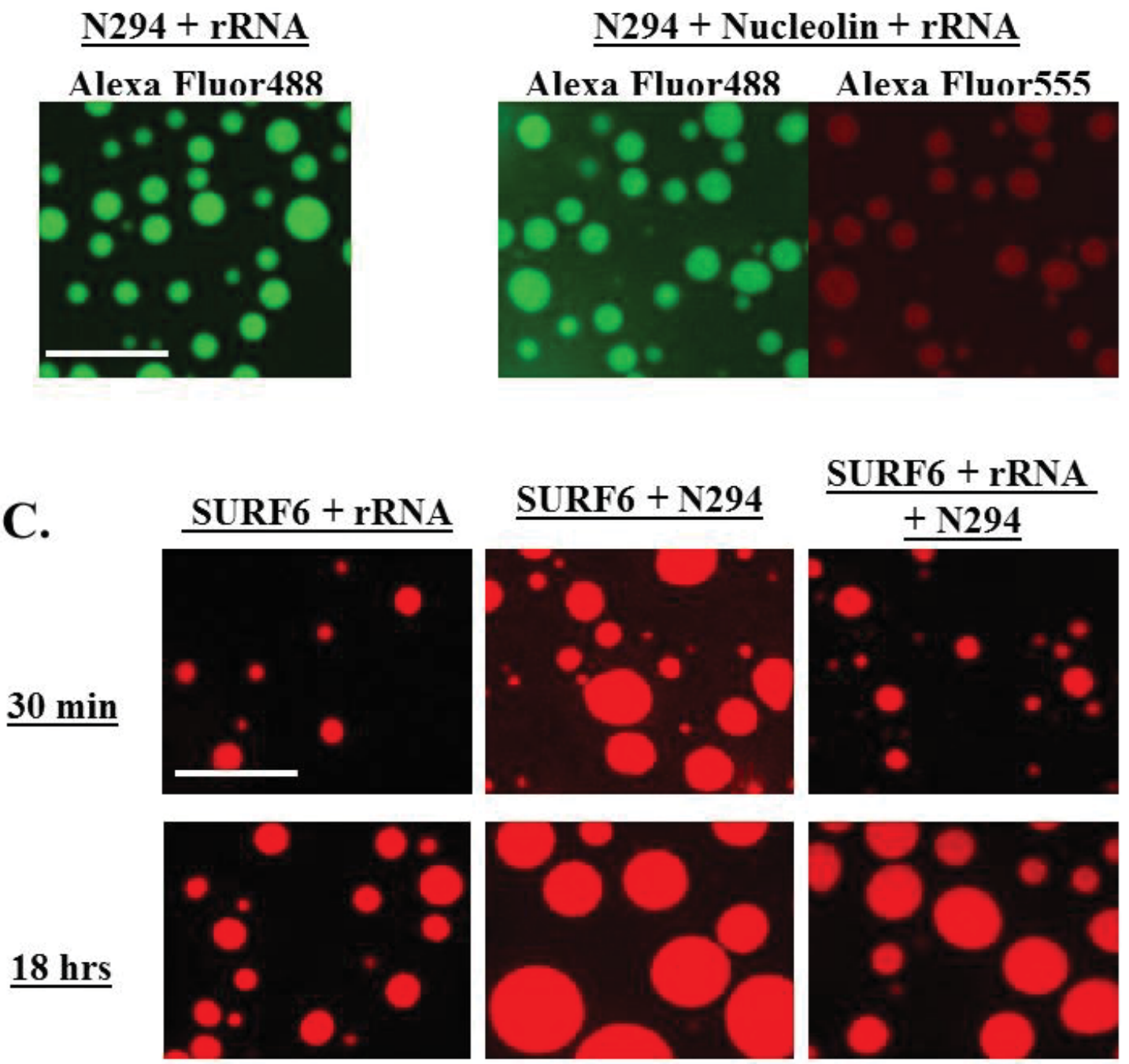

Figure 3-6. rRNA Promotes LLPS with NPM1 and R-Proteins

A. $10 \mu \mathrm{M}$ N294, spiked with $1 \mu \mathrm{M}$ A488-N294, with $50 \mu \mathrm{g} / \mathrm{mL}$ rRNA B. $10 \mu \mathrm{M}$ N294, spiked with $1 \mu \mathrm{M}$ A488-N294, with $10 \mu \mathrm{M}$ A555-Nucleolin, and $50 \mu \mathrm{g} / \mathrm{mL}$ rRNA. C. Confocal images collected 30 minutes after mixing and after overnight incubation at room temperature of $20 \mu \mathrm{M}$ SURF6 (spiked with $2 \mu \mathrm{M}$ Alexa Fluor555 SURF6) with $100 \mu \mathrm{g} / \mathrm{mL}$ wheat germ rRNA (left), $20 \mu \mathrm{M} \mathrm{N} 294$ (middle), and the tertiary mixture (right). Scale bar: $10 \mu \mathrm{m}$. 
interactions (i.e., through addition of rRNA to protein droplets and manipulating electrostatic interactions) affected protein dynamics within the droplets. To do this, we performed a series of fluorescent recovery after photobleaching (FRAP) microscopy experiments. FRAP reports on the rate at which proteins diffuse within the droplets, as well as the fraction of the protein molecules that are able to diffuse within the droplet (i.e., mobile fraction).

We began by testing the effects of varying salt concentration, and thus electrostatic interactions, on protein dynamics. We wanted to modulate the valency of the system, so we chose to use SURF6 for these experiments as this R-protein has the largest number of R-motifs, and thus the largest number of possible NPM1 binding sites (Figure 3-5a). Droplets were made with only one labeled protein at a time to prevent fluorescence resonance energy transfer (FRET) between the two fluorophores (Alexa Fluor488 for NPM1 and Alexa Fluor555 for SURF6) at a 1:1 ratio at 5, 10, and $20 \mu \mathrm{M}$. Droplets were then imaged by confocal microscopy thirty minutes after mixing (Figure 3-7). Only large droplets made at $20 \mu \mathrm{M}$ protein were photobleached as these droplets at higher $\mathrm{NaCl}$ concentrations were still large enough for FRAP experiments. Regions of roughly 0.67 $\mu \mathrm{m}^{2}$ at the center of the droplet were photobleached and FRAP was monitored until recovery curves plateaued. Although LLPS was observed at 150 and $175 \mathrm{mM} \mathrm{NaCl}$, the observed droplets were too small to obtain accurate FRAP measurements as the bleached region would occupy most of the droplet. At $200 \mathrm{mM} \mathrm{NaCl}$, droplets no longer formed. As expected, when the $\mathrm{NaCl}$ concentration was increased, SURF6 mobility increased from $80.3 \%$ to $98.0 \%(\mathrm{p}<0.001)$ and the apparent rate of diffusion increased from approximately $0.01 \mu \mathrm{m}^{2} / \mathrm{s}$ to $0.06 \mu \mathrm{m}^{2} / \mathrm{s}(\mathrm{p}<0.001)$ (Figure 3-8). However, for N294, only the apparent rate of diffusion increased with $\mathrm{NaCl}$ concentrations with an average from $0.02 \mu \mathrm{m}^{2} / \mathrm{s}$ to $0.03 \mu \mathrm{m}^{2} / \mathrm{s}(\mathrm{p}=0.001)$, whereas the percent mobile fraction decreased on average from $89.4 \%$ to $76.7 \%(\mathrm{p}=0.001)$ as the $\mathrm{NaCl}$ concentration increased from $75 \mathrm{mM}$ to $125 \mathrm{mM}$ (Figure 3-9).

After analyzing the effects of electrostatic interactions on N294 droplets, we next determined how rRNA affects protein dynamics within droplets. We already knew from the R-peptides and R-protein droplet experiments discussed above that rRNA can interact with and phase separate with R-motifs. However, when examining the phase separation behavior of rRNA with R-motif-containing peptides or proteins, we observed either smaller puncta or smaller droplets with R-peptides and R-proteins, respectively. This led us to believe that protein/protein interactions differ from protein-rRNA interactions and that we can therefore also modulate protein dynamics by altering protein and rRNA concentrations within the droplets. To test this hypothesis, we utilized one of the Rproteins that was able to phase separate with N294, but did not form droplets that readily fused with one another, GNL2 (Figure 3-5). Following the same protocol for FRAP experiments described above, we analyzed droplets composed of N294/rRNA, N294/GNL2, and N294/GNL2/rRNA. Droplets composed of only N294 and rRNA were round and fused readily, whereas droplets composed of N294 and GNL2, although round, did not fuse with one another but rather docked on each other much like beads on a string (Figure 3-10a). This "beads on a string" appearance was diminished when rRNA was incorporated into the droplets (Figure 3-10a). A488-N294 and A555-GNL2 were then 


\section{$[\mathrm{NaCl}]$}

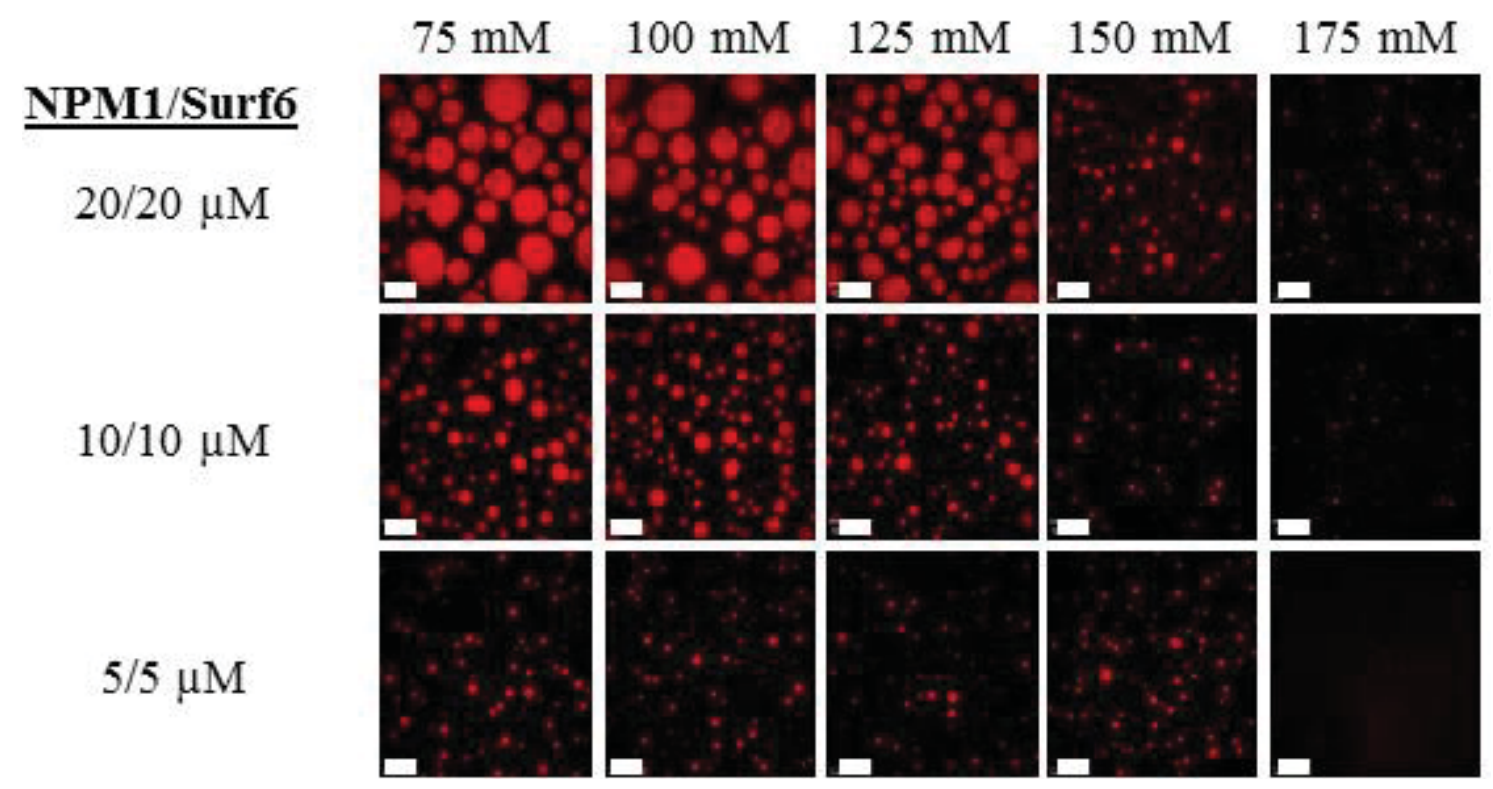

Figure 3-7. Salt Dependence of Surf6/N294 Droplets

Confocal images of N294/SURF6 mixtures at various salt concentrations. Images were acquired 15 minutes after mixing. Scale Bar: $5 \mu \mathrm{m}$ 

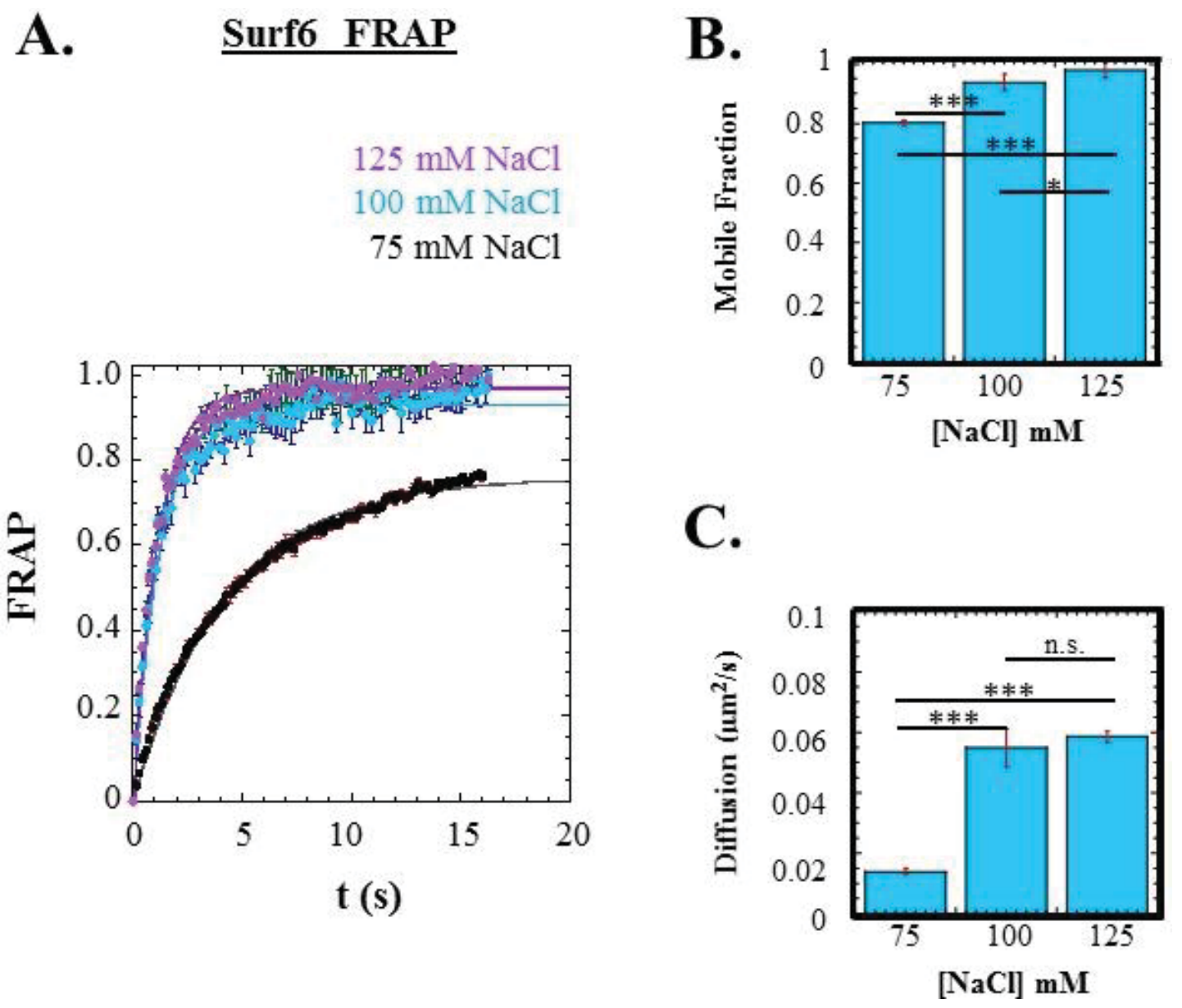

Figure 3-8. Effects of Electrostatic Interactions of Surf6 Dynamics within N294/Surf6 Droplets

A. FRAP curve fit to a single exponential. B. Mobile fraction of Surf6 calculated from the FRAP curve fit to a single exponential. C. Apparent rate of diffusion calculated from the recovery timescale, $\tau$, and the bleached radius. $* * * p<0.001, * * p<0.01, * p<0.05$, n.s. not significant. 

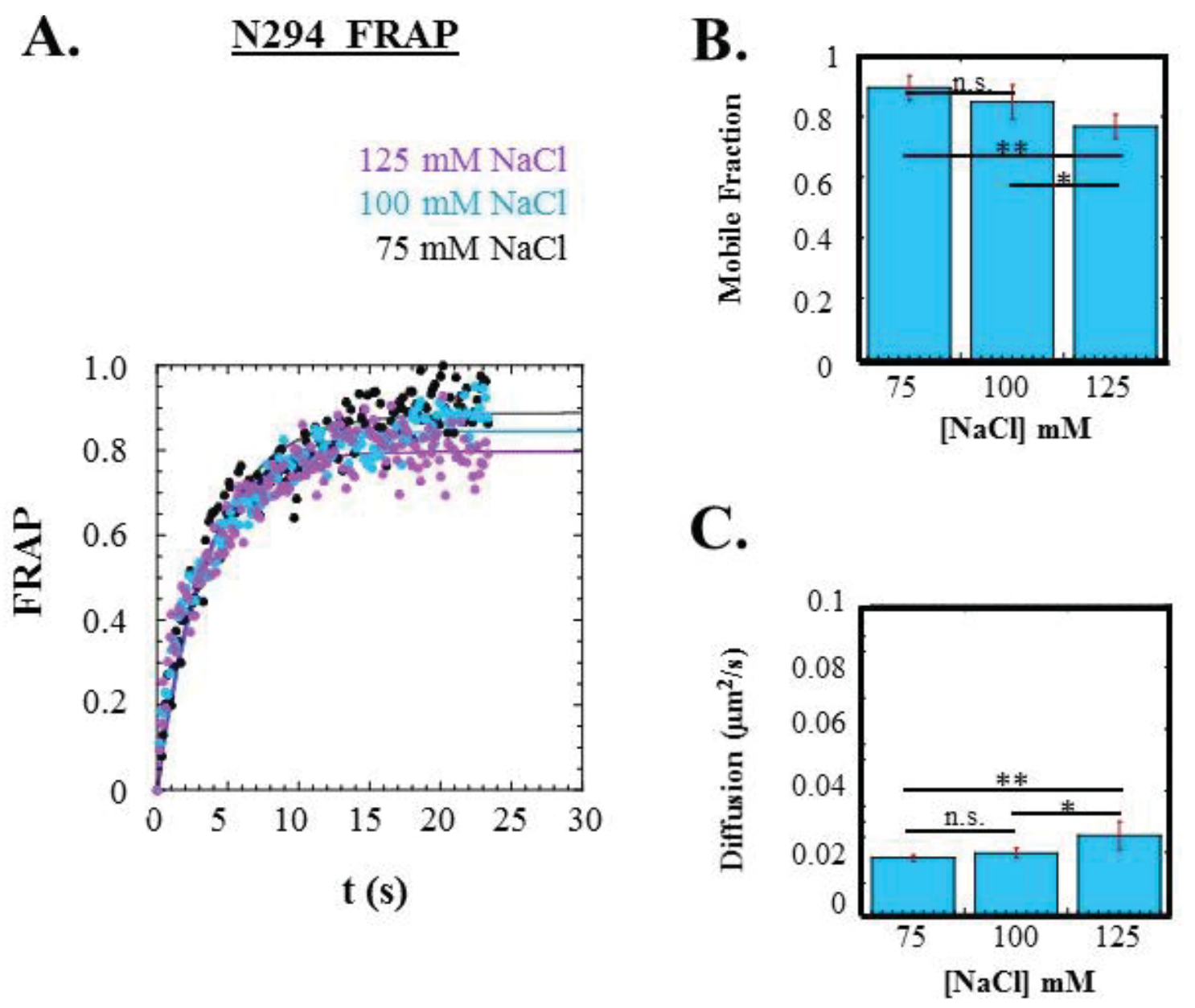

Figure 3-9. Effects of Electrostatic Interactions of N294 Dynamics within N294/Surf6 Droplets

A. FRAP curve fit to a single exponential. B. Mobile fraction of Surf6 calculated from the FRAP curve fit to a single exponential. C. Apparent rate of diffusion calculated from the recovery timescale, $\tau$, and the bleached radius. $* * * p<0.001, * * p<0.01, * p<0.05$, n.s. not significant. 
A.

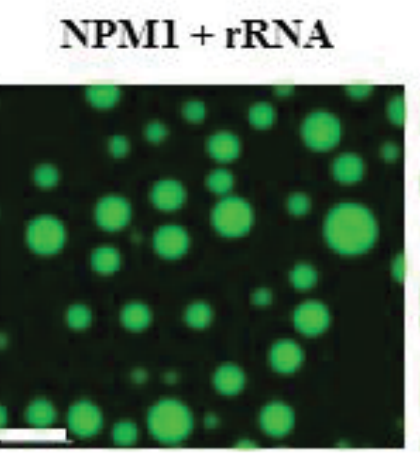

NPMl + GNL2

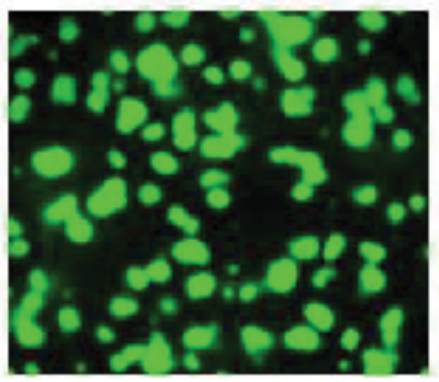

NPMI + GNL2

+ rRNA

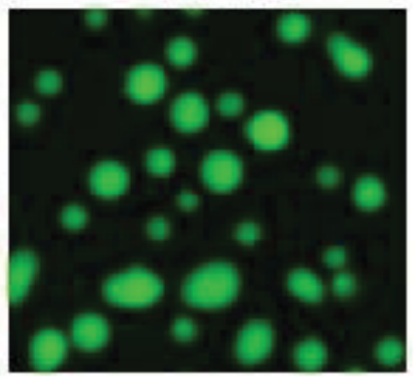

B.
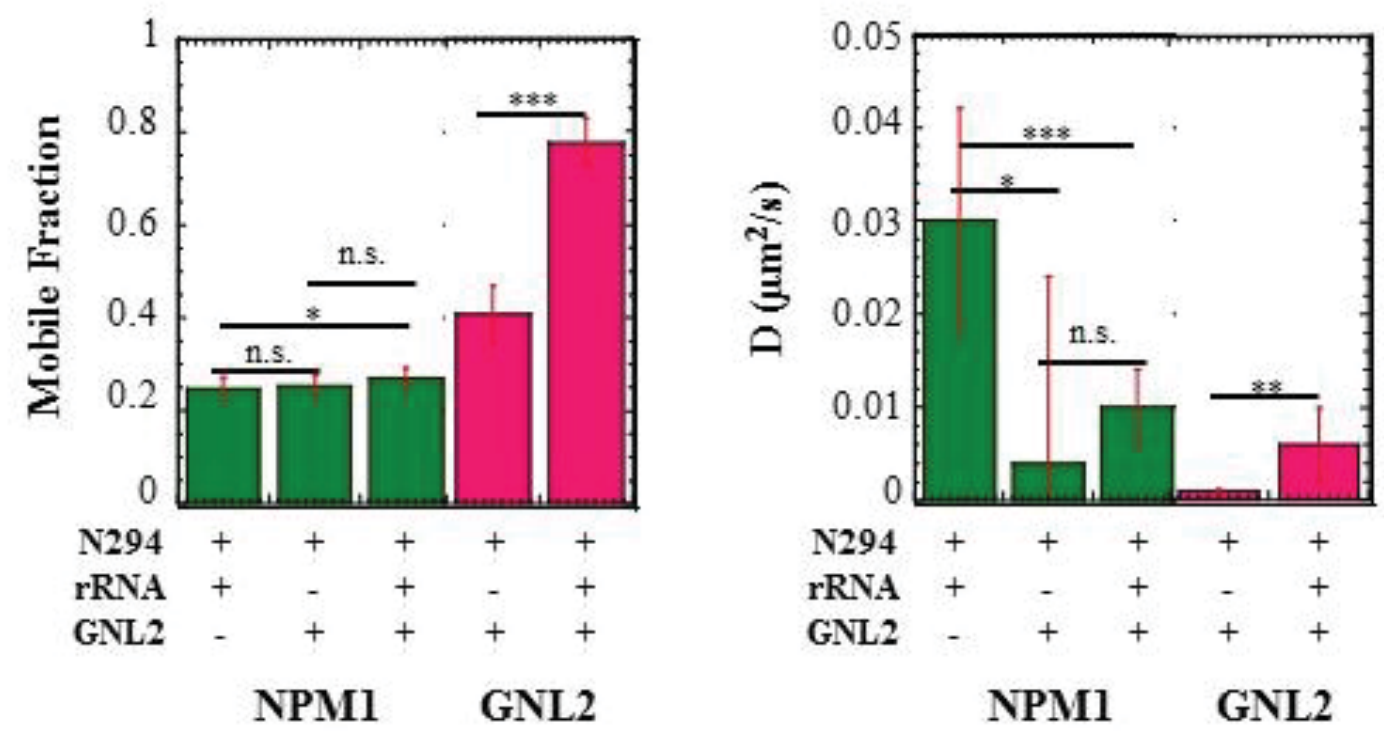

Figure 3-10. NPM1/GNL2 Droplets Can Be Modulated by the Addition of rRNA A. $10 \mu \mathrm{M}$ N294 (spiked with $1 \mu \mathrm{M}$ Alexa Fluor488 N294) mixed with $50 \mu \mathrm{g} / \mathrm{mL}$ wheat germ rRNA (left), $20 \mu \mathrm{M}$ GNL2 (middle), and the tertiary mixture. Images were acquired 2.5 hours after mixing. Scale bar: $5 \mu \mathrm{m}$. B. Graphs comparing the differences in N294 (green) and GNL2 (pink) mobile fraction (left) and diffusion coefficients (right) acquired from FRAP data. $\mathrm{N}=10$. ${ }^{* * *} \mathrm{p}<0.001,{ }^{*} \mathrm{p}<0.01,{ }^{*} \mathrm{p}<0.05$, n.s. not significant. 
photobleached, separately, to obtain FRAP curves from which protein mobility and diffusion rates were calculated. N294 mobility only increased slightly and when GNL2 was incorporated into the droplets when compared to N294/rRNA droplets ( $p=0.0464$ ), whereas the addition of rRNA to N294/GNL2 droplets had no effect on N294 mobility or the rate of diffusion (Figure 3-10b). N294 diffusion was drastically slower $(0.004 \pm 0.02$ $\mu \mathrm{m}^{2} / \mathrm{s}$ versus $\left.0.03 \pm 0.12 \mu \mathrm{m}^{2} / \mathrm{s}, \mathrm{p}=0.0024\right)$ when GNL2 was incorporated into droplets than in N294/rRNA droplets alone (Figure 3-10b). Addition of rRNA to droplets, however, had a more drastic effect on GNL2 mobility and diffusion; GNL2 mobility increased from $40.8 \pm 6.2 \%$ to $77.8 \pm 5.1 \%$ ( $<<0.0001$ ), and GNL2 diffusion increased from $0.001 \pm 0.0002 \mu \mathrm{m}^{2} / \mathrm{s}$ to $0.006 \pm .004 \mu \mathrm{m}^{2} / \mathrm{s}(\mathrm{p}=0.0009)$ when rRNA was a part of the droplet network (Figure 3-10b). 


\section{CHAPTER 4. DISCUSSION}

Eukaryotic cells harbor both membrane-bound and membrane-less organelles. Unlike the classical membrane-bound organelles, membrane-less organelles lack a tangible barrier separating their components from the nucleo- or cytoplasm. Despite the knowledge of their existence for more than a century, their assembly, function, and maintenance are still poorly understood. It has recently become widely accepted that this class of organelles arise through LLPS of their components creating a fluid environment within them (Brangwynne, et. al. 2011; Feric, et. al., 2016; Guo and Shorter, 2015; Han, et. al., 2012; Mitrea, et. al., 2016; Molliex, et. al, 2015; Nott, et. al., 2015; Weber and Brangwynne, 2015). The largest membrane-less organelle, the nucleolus, is located in the nucleoplasm and is the site of ribosome biogenesis and a sensor for cellular stress (Tafforeau, et. al., 2013). Despite the lack of a lipid membrane, nucleoli are organized into three compartments: the fibrillar center (FC), the dense fibrillar component (DFC), and the granular component (GC). Of these compartments, the GC (Brangwynne, et. al., 2011) and, more recently, the DFC (Feric, et. al., 2016) have been shown to exhibit liquid-like properties. Nucleophosmin 1 (NPM1) is highly enriched in the GC and exhibits structural features found to promote LLPS, specifically multivalent acidic tracts, a nucleic acid binding domain, and a disordered region (Elbaum-Garfinkle, et. al., 2015; Li, et. al., 2012; Molliex et. al., 2015). It has previously been shown that the acidic tracts of NPM1 interact with R-rich motifs (Mitrea, et. al., 2014) and the CTD can bind to rRNA (Wang, et. al., 1994). Based on these previous observations, we hypothesized that NPM1 can undergo LLPS with its nucleolar binding partners (i.e., rRNA and R-rich proteins), thus creating a heterogeneous network of weak and transient interactions that contribute to the liquid-like behavior of nucleoli.

Here, we showed that multivalent R-motifs are enriched in NPM1 binding partners, many of which are also nucleolar proteins. We have shown that weak, electrostatic interactions between NPM1 and R-rich motifs promote LLPS in vitro, and that phase separation is dependent on multivalency, protein concentration, and buffer ionic strength. Furthermore, we showed how droplet morphology was modulated by altering the spacing between R-motifs, changing buffer ionic strength, and incorporating rRNA in the droplets. Using microscopic techniques, we then showed how protein dynamics within droplets changes in response to changes in ionic strength and when rRNA is added to the droplets.

\section{NPM1 Interacts with a Variety of Arginine-Rich Motif Nucleolar Proteins through Weak, Electrostatic Interactions}

Through the analysis of a list of NPM1 binding partners, we discovered that the majority of NPM1 binding partners are enriched in multivalent R-motifs, compared to the majority of proteins in the human proteome $(\mathrm{p}<0.0001)$, and that many of these proteins are known to localize to the nucleolus. These results suggested that the presence of multivalent R-motifs is sufficient for proteins to, i) bind to NPM1 and ii) localize within 
the nucleolus. In order to promote phase separation but also maintain a liquid-like environment, interactions must be strong enough to form larger molecular assemblies, but also weak enough to allow proteins to remain dynamic (Li, et. al., 2012). Previous work published by the Kriwacki lab showed that R-rich motifs bind to at least two of the three acidic tracts (A1 and A2) within NPM1 (Mitrea, et. al., 2014), and here we showed that R-motif peptides bind to NPM1 with low micromolar dissociation constants.

Furthermore, the binding affinities decreased when the valency of the R-peptide was decreased. Additionally, for the RPL5 peptides, the presence of a second R-motif not only increased the affinity for NPM1 but also increased the total amount that bound to N130; for example, more of the wild type RPL5 peptide bound to N130 than the RPL5RA mutant. Furthermore, when peptides containing more than two R-motifs (RPL23a ${ }^{47-}$ ${ }^{68}$ ) or more extensive R-motifs (GNL2 ${ }^{682-709}$ ) were titrated into N130, the ITC data appeared to exhibit multiple binding events, suggesting that the different R-motifs could bind to N130 but with different affinities. These observations led us to hypothesize that that weak, electrostatic interactions between multivalent R-motifs and NPM1 would promote LLPS, as seen by others with other proteins (Banajade and Rosen, 2016; Li, et. al., 2012; Su, et. al., 2016).

\section{Weak, Multivalent Electrostatic Interactions Promote In Vitro Phase Separation}

We next sought to test the hypothesis that weak, electrostatic interactions between multivalent R-motifs and NPM1 acidic tracts causes LLPS. We initially proved, using a minimalistic system, that multivalent interactions between R-motifs and NPM1 acidic tracts do promote LLPS in vitro, as observed by microscopy, and that the observed phase transition was dependent on a highly multivalent system (i.e., at least two R-motifs per peptide and two acidic per NPM1 monomer), as observed by changes in turbidity (Mitrea, et. al., 2016). Additionally, each of the peptides were able to form liquid-like droplets that fused with one another and grew over time, however the threshold for phase separation and size of the droplets varied among peptides. The peptide with the lowest Rmotif valency (e.g., with the smallest number of R-motifs and smallest total number of arginine residues within them), RPL5 ${ }^{21-37}$, exhibited the highest LLPS concentration threshold, meaning higher concentrations of N130 and RPL5 ${ }^{21-37}$ were required to promote LLPS. GNL2 ${ }^{682-709}$ and SURF6 ${ }^{299-326}$ exhibited much lower concentration thresholds and were able to form droplets with as little as $5 \mu \mathrm{M}$ N130, most likely due to more arginine residues within their R-motifs. Even though each of these peptides experienced different concentration thresholds, droplet formation would not occur unless excess peptide was present as, according to our definition, these peptides only had two Rmotifs. One the other hand, RPL23a ${ }^{47-68}$, which contains three R-motifs that could potentially bind to N130, was able to phase separate with N130 at low concentrations (Figure 3-2) and at a 1:1 ratio of N130 to peptide. Additionally, these droplets appeared larger in size and were more abundant than droplets formed from the other peptides. To further understand how sequence features can dictate droplet size, we analyzed two additional RPL5-like peptides that were engineered to have longer linkers (comprised mostly of Gly-Ser repeats) between the two R-motifs. Interestingly, increasing the linker length was associated with increases droplet size (Figure 3-3). The results of these 
experiments show that increasing the valency of the system decreases the phase separation threshold to lower concentrations and NPM1:R-motif peptide molar ratios, just as has reported by others for other systems (Li, et. al., 2012). Furthermore, these results suggest that differences in valency (i.e., the number of R-motifs) and distance between these R-motifs among various R-rich nucleolar NPM1 binding partners are associated with varied propensities to undergo LLPS with NPM1 and possibly to heterogeneity of the fluid properties within the GC region of nucleoli.

The observation that NPM1 is not required for ribosome biogenesis (Amin, et. al., 2008; Holmberg, et. al., 2014) suggested that the liquid-like features of the GC region of the nucleolus may arise through phase separation of nucleolar components apart from NPM1. To test this idea, we determined whether interactions between proteins with multivalent R-motifs and rRNA caused LLPS. Using the same peptides as with N130 and wheat germ rRNA, we titrated increasing amounts of peptide into rRNA, and vice versa, and measured changes in turbidity. We observed that increases turbidity during these titration and then used microscopy to determine whether droplets formed because turbidity only indicates a change in particle size and/or number, not particle shape and fluidity. Using microscopy, we observed that instead of droplets, as with N130, Rpeptides and rRNA phase separated into small puncta $(\sim 1 \mu \mathrm{m}$ in diameter $)$ that did not fuse. Interestingly, even though NPM1 is not required for ribosome biogenesis, without NPM1, the GC of nucleoli do not assemble properly and appear distorted (Amin, et. al., 2008). Altogether, these data suggest that NPM1 plays a role in mediating LLPS by acting as a scaffold to which R-rich proteins can form crosslinks with the A-tracts within NPM1 pentamers. Furthermore, as R-peptides and rRNA alone and N122 and peptides alone could not form liquid-like droplets, we hypothesize that droplet formation requires the high multivalency associated with A-tracts within pentameric N130.

\section{NPM1 Phase Separates with Nucleolar Arginine-Rich Motif Containing Proteins and rRNA to Form Liquid-Like In Vitro Droplets}

Moving beyond our minimalistic system with peptides and truncated NPM1, we began screening for droplet formation using a more physiologically relevant and complex system using full-length NPM1 (N294) and nucleolar R-protein constructs identified as NPM1 binding partners (SURF6 ${ }^{1-182}$, GNL2 $^{630-731}$, RPL23a $^{1-156}$, and Nucleolin ${ }^{610-709}$ ). SURF6 is a known nucleolar protein, disordered, and important for ribosome biogenesis (Magoulas, et. al., 1998; Romanova, et. al., 2006). A specific function for SURF6 has not yet been determined, but it is quite possible that SURF6 functions as a disordered nucleolar matrix protein to contribute to the liquid-like properties of nucleoli. GNL2 is a nucleolar GTPase required for release of pre-60S ribosomal particles from the nucleolus and contains disordered $\mathrm{N}$ - and $\mathrm{C}$-terminal regions harboring multivalent $\mathrm{R}$-motifs (Matsuo, et. al., 2014). RPL23a is a large ribosomal subunit protein required for intermediate pre-rRNA processing steps, and contains a disordered N-terminal region containing R-motifs (Gamalinda, et. al., 2014). Nucleolin is a multifunctional nucleolar protein with features similar to those of NPM1. Specifically, nucleolin has a disordered $\mathrm{N}$-terminal region containing multiple acidic tracts, a folded central region with multiple 
RNA binding domains, and a disordered C-terminal region containing stretches of glycine/arginine repeats known as GAR domains (Tajrishi, et. al., 2011). Each of these proteins plays distinct roles within the nucleolus and therefore may contribute differently to the liquid-like nucleolar environment.

Using confocal microscopy as with our minimalistic system, we showed that each of the R-proteins phase separated with N294. However, to our surprise, not all R-proteins phase separated with N294 to form liquid-like droplets as did the peptides. SURF6 and RPL23a formed highly "fuse-able" droplets, while GNL2 formed less fluid droplets that did not readily fuse with each other. Additionally, nucleolin and NPM1 phase separated into a solid-like state rather than a liquid-droplet state. Thus, we propose that a hierarchy of R-motifs, exhibiting a range of affinities for NPM1, exists within nucleolar proteins, which leads to a heterogeneous network of interactions with NPM1 within droplets and possibly the nucleolus.

NPM1 also contains a C-terminal nucleic acid binding domain that has been shown to interact with rRNA (Wang, et. al., 1994). Here, we have shown that these interactions cause phase separation to form liquid-like droplets that fuse over time. Additionally, we have shown that nucleolin, which also contains RNA binding domains (i.e., structured RRM domains and disordered GAR domains), can be incorporated into N294/rRNA droplets even though nucleolin and N294 did not form droplets in the absence of rRNA. Nucleolin and NPM1 both exhibit acidic tracts and can bind to rRNA; however, nucleolin is not known to self-oligomerize. It is possible that, under conditions other than those tested here, nucleolin does phase separate with rRNA or R-motif proteins in the absence of NPM1; however, if oligomerization is required to create a highly multivalent scaffold as seen with NPM1 (Mitrea, et. al., 2016), LLPS with nucleolin may not be possible. Additional experiments will be needed, however, to determine if nucleolin and rRNA, and nucleolin and R-proteins, undergo LLPS without NPM1. Additionally, unlike our results with short R-motif containing peptides, not all R-proteins required NPM1 to undergo LLPS with rRNA, as shown by the observations that SURF6 and rRNA phase separated to form liquid-like droplets in the absence of NPM1. Unlike the short peptides, SURF6 is highly multivalent with six R-motifs within the N-terminal region of the protein that can potentially interact with rRNA. This suggests that the Rmotifs are spaced sufficiently far apart to create the crosslinks between rRNA molecules required to maintain a liquid-like phase. In the future, experiments using a series of SURF6 constructs in which varied numbers of R-motifs are mutated to alter rRNA binding will need to be performed to test this hypothesis. Overall, these data suggest that NPM1, R-proteins, and rRNA form a network of multivalent interactions that promote LLPS and, thus, a dynamic liquid-like phase in nucleoli. Thus, altering R-protein concentration, valency, and affinity could provide a means to tune the fluid environment of droplets and, presumably, nucleoli (i.e., viscosity, surface tension and protein dynamics). 


\section{Protein Dynamics within Droplets Can Be Modulated by Electrostatic Interactions}

We have shown that LLPS of NPM1 with R-proteins arises from a network of weak, electrostatic interactions between oppositely charged A-tracts and R-motifs, respectively, and that droplet morphology differs between constructs with varying degrees of valency. Therefore, we wanted to determine how changing valency alters protein dynamics within the liquid-like droplets. SURF6 exhibits the largest number of R-motifs, six in total, and was thus used in experiments in which ionic strength was varied to modulate multivalency for binding to NPM1. As expected, when the NaCl concentrations was increased, droplet size decreased and eventually, at $200 \mathrm{mM} \mathrm{NaCl}$, the electrostatic interactions required for droplet formation were disrupted. Interestingly, by monitoring FRAP, we observed different dynamics for NPM1 and SURF6 as a function of $\mathrm{NaCl}$ concentration. Specifically, as expected, when the $\mathrm{NaCl}$ concentration was increased, the mobile fraction (i.e., amount of protein able to move throughout the droplet) of SURF6 also increased. Additionally, this increase in mobile SURF6 was accompanied with an increase in the rate of SURF6 diffusion. More simply, the disruption of electrostatic interactions between NPM1 and SURF6 liberated more SURF6, and, since diffusion rates are inversely proportional to the particle size, this suggests that the avidity of interactions between SURF6 and NPM1 was reduced. NPM1, on the other hand, did not behave similarly. With NPM1, increasing the $\mathrm{NaCl}$

concentration actually decreased the amount of mobile NPM1 and only slightly increased the rate at which NPM1 diffused within droplets. Although these results seem contradictory, it is possible that at a lower salt concentration, NPM1 pentamers may become more compact, blocking the weaker acidic tract (A3) by the basic $\mathrm{C}$-terminal region and therefore promoting the stronger interactions with A1 and A2 with each SURF6 R-motif. Recent, unpublished data suggests an autoinhibitory mechanism within NPM1 where the basic CTD blocks A-tracts via homotypic intra- and inter-molecular interaction (Mitrea, Cika \& Kriwacki, unpublished). Likewise, as salt concentrations are increased, electrostatic interactions between NPM1 and SURF6, as well as NPM1 with itself, are disrupted, and therefore the network within the droplet and NPM1 opens up, becoming less compact, and exposing the weaker A3 (Figure 4-1). Now there is more room and more available acidic tracts for NPM1 to participate in crosslinking with SURF6, however with less R-motifs, so droplets therefore decrease in size as valency decreases. To test this hypothesis, salt titrations using an NPM1 construct lacking the basic $\mathrm{C}$-terminal region and thus an available $\mathrm{A} 3$ at all salt concentrations need to preformed and compared to wild type NPM1.

\section{Protein Dynamics within Droplets Can Be Modulated by rRNA}

Nucleoli are the site for ribosome biogenesis, and thus contain large amounts of rRNA. We next examined how rRNA affects protein dynamics within droplets. In order to keep the system as simple as possible while still allowing each component to interact with one another, we analyzed droplets composed of N294 (containing the rRNA binding CTD), GNL2 (containing only one multivalent R-motif that can interact with both NPM1 and rRNA, but only forms droplets with NPM1), and rRNA. Droplets comprised of all 


\section{Compact \\ Network}

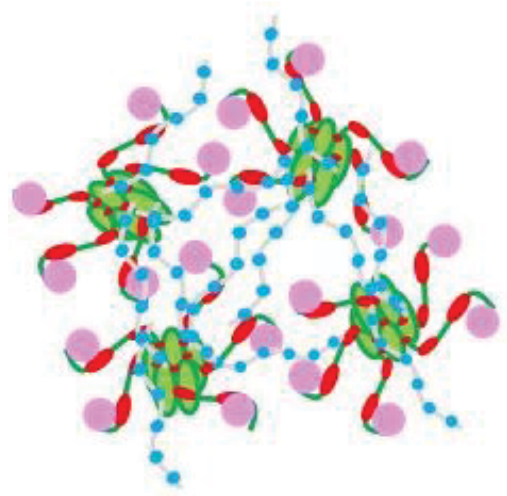

\section{Open} Network

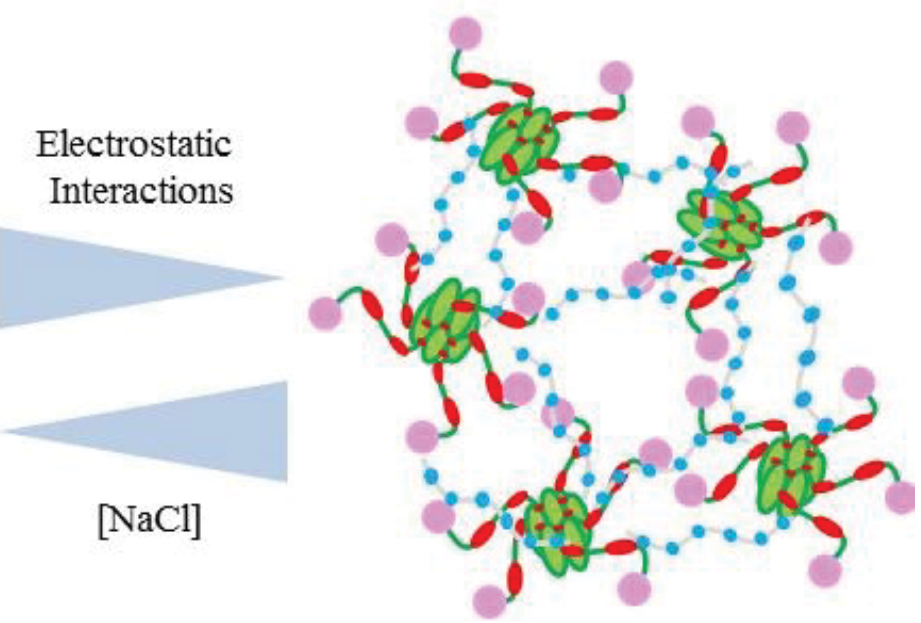

Figure 4-1. NPM1 Droplet Network Can Be Tuned by Modulating Electrostatic Interactions

Low salt conditions (left) increases electrostatic interactions and promotes a more compact NPM1 conformation. NPM1 CTD (pink) blocks acidic tracts (red), preventing R-motifs (blue) from forming additional crosslinks. Increasing salt concentrations disrupts electrostatic interactions (right) promotes a less compact NPM1 conformation and droplet network, giving R-motifs access to additional acidic tracts. 
three components readily fused with one another, whereas droplets comprised of only N294 and GNL2 did not exhibit fusion. The increased fluidity of ternary droplets was accompanied by an increase in the fraction of GNL2 that was mobile and the rate at which it diffused within droplets, in comparison with the behavior of GLN2 within binary droplets with just NPM1. The fraction of mobile NPM1, on the other hand, was similar in binary droplets comprised of N294 and rRNA, and N294 and GNL2, and increased only slightly in ternary droplets (Figure 3-10). Furthermore, NPM1 diffusion decreased when GNL2 was incorporated into droplets. Although the fraction of mobile NPM1 was slightly increased when both GNL2 and rRNA were present, NPM1 exhibited a reduced diffusion rate. This could be due to, in the ternary droplet, rRNA competing with NPM1 for GNL2 thus disrupting rRNA and GNL2 crosslinks between pentamers and slightly increasing the mobile fraction of NPM1. However, here GNL2 is also present which also binds to the freely diffusing NPM1 fraction, thus reducing the rate of NPM1 diffusion. When all three components are present, crosslinks are formed between NPM1 and both rRNA and GNL2, which in turn frees GNL2 from NPM1 and increases GNL2 mobility and its rate of diffusion (Figure 4-2). To further understand the nature of the network making up the ternary droplets it would be informative to have labeled rRNA in order to monitor changes in rRNA dynamics with and without GNL2.

These data show how NPM1 binding partners, especially those known to reside within the nucleolus, are enriched in multivalent R-motifs, which suggests a common mechanism for nucleolar localization of proteins. These proteins, through their R-motifs, are able to interact weakly and transiently through electrostatic interactions with the multivalent acidic tracts within NPM1. Furthermore, these multivalent interactions promote LLPS in vitro, suggesting an explanation for the liquid-like behavior of nucleoli (Brangwynne, et. al., 2011; Feric, et. al., 2016). Furthermore, the properties of the liquidlike phase of NPM1-containing droplets can be manipulated by altering R-motif valency, the number of amino acids between R-motifs, and electrostatic interactions, and through the incorporation of rRNA. These preliminary data provide additional insight into the biophysical properties and molecular mechanisms governing phase separation and, thus, expand our understanding of membrane-less organelle formation and function.

\section{Future Directions}

Although these results offer a deeper understanding for LLPS and membrane-less organelles, there is still much work to be done to be able to connect molecular properties (i.e., sequence features and protein structure) to biological functions (i.e., processes associated with RNA metabolism, ribosome biogenesis, stress responses, etc.). To gain a more clear understanding of LLPS and nucleolar structure and function, additional experiments are needed to measure other biophysical properties of in vitro droplets (i.e., viscosity and surface tension). Others have begun to study changes in these parameters using in vitro systems pertaining to nucleoli and P granules (Elbaum-Garfinkle, et. al., 2015; Feric, et. al., 2016). We have suggested that SURF6, and other similar nucleolar proteins (i.e., exhibit disordered regions enriched in multivalent R-motifs but have no known function), may mainly modulate the liquid-like nature of nucleolar matrix. To gain 


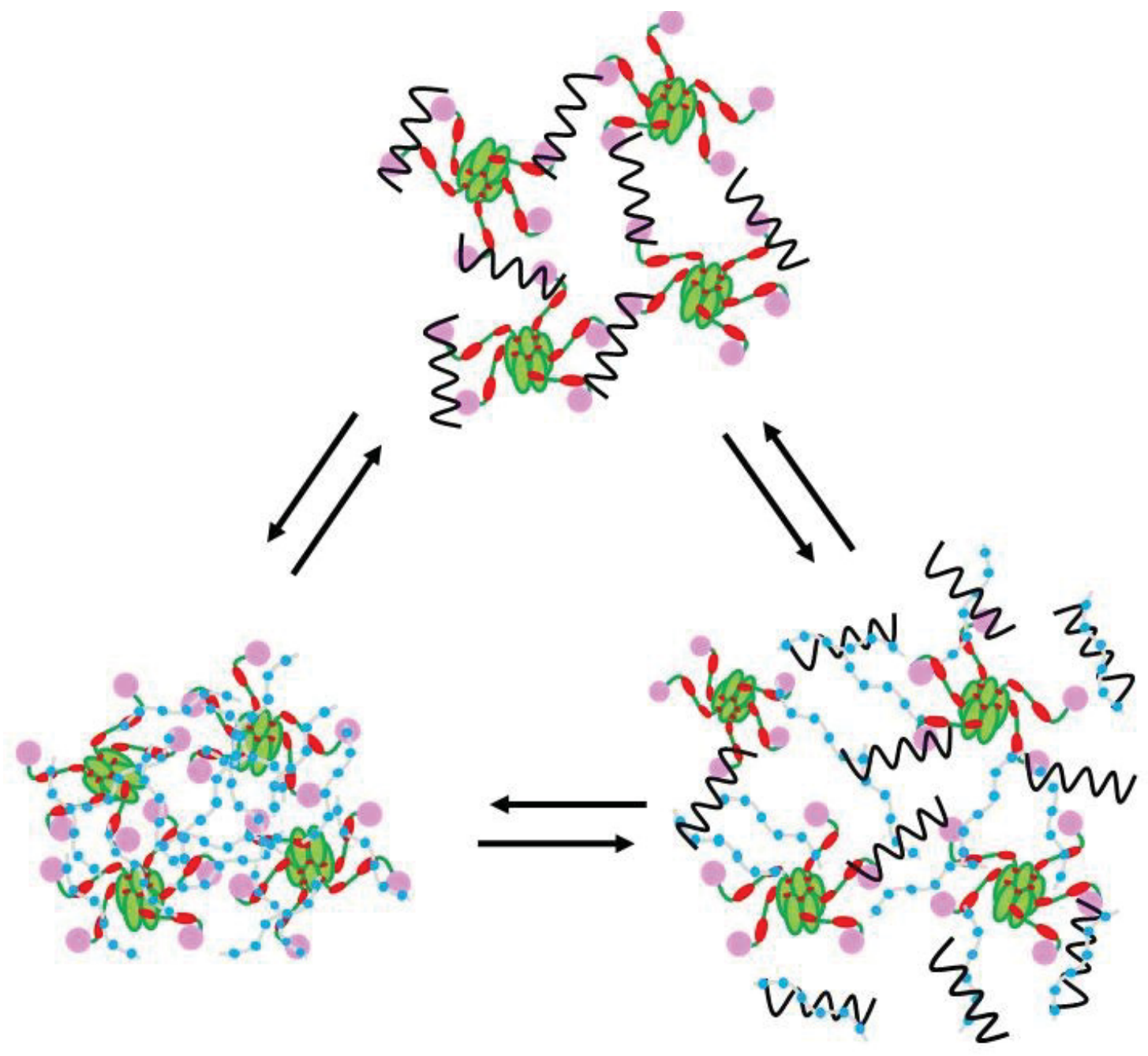

Figure 4-2. Protein Dynamics Can Be Tuned by the Addition of rRNA

Droplets consisting of NPM1 and R-proteins form a more extensive network resulting in a dense liquid-like phase. The addition of rRNA (black) disrupts some of the crosslinks by competing for R-proteins with NPM1. This results in a less dense liquid-like phase and increases R-protein dynamics within droplets and droplet fluidity. 
further insight into the roles these proteins play and the effect of their R-motif valency and linker length between R-motifs, a series of R-protein mutants where individual Rmotifs are mutated should be studied (i.e., measuring protein dynamics within droplets and, potentially, droplet viscosity and surface tension) and compared to the wild-type proteins as discussed here. These experiments will give insight into the types of interactions between NPM1 and R-proteins which promote LLPS and how to modulate droplet properties by altering the network of interactions making up the liquid-like phase. For the R-protein mutants that alter droplet material properties, we can then incorporate these mutant proteins into live cells to test if these molecular changes cause a biological response. In cells transfected with the mutant R-proteins, FRAP experiments in live cells monitoring other nucleolar proteins, for instance NPM1, would allow us to measure changes in NPM1 nucleolar diffusion in response to changes in valency of nucleolar matrix proteins. We would also analyze nucleolar size, shape, and number in order to relate changes in the structure of the nucleolar matrix to changes in nucleolar integrity. rRNA processing, an aspect of ribosome biogenesis, could be monitored using radioactively labeled methionine to label newly transcribed rRNA (Olausson, et. al., 2014). Together, these experiments will give novel insight into the types of interactions that make up nucleoli and promote the observed liquid-like behavior; furthermore, these experiments will allow us to relate the biophysical properties observed with in vitro droplets to the molecular properties and functional roles of nucleoli.

\section{Broader Implications}

It is believed that membrane-less organelles, including nucleoli, arise through LLPS of their components. However, the underlying molecular mechanisms governing phase separation are currently not clearly understood. By studying the biophysical properties governing LLPS with NPM1 in vitro, we can gain insight into the molecular mechanisms governing LLPS in vivo. Furthermore, this knowledge provides a molecular explanation for the localization of nucleolar proteins through LLPS via multivalent interactions between acidic tracts (in NPM1) and R-motifs (in R-proteins). Many disordered nucleolar proteins contain patches of acidic residues or R-motifs, but their function within the nucleolus is unknown. Our results with NPM1 and R-proteins suggest

a potential nucleolar role for these proteins, as nucleolar matrix proteins that promote a liquid-like environment. 


\section{LIST OF REFERENCES}

Amen, T., \& Kaganovich, D. (2015). Dynamic droplets: the role of cytoplasmic inclusions in stress, function, and disease. Cell Mol Life Sci, 72(3), 401-415.

Amin, M. A., Matsunaga, S., Uchiyama, S. \& Fukui, K. (2008). Depletion of nucleophosmin leads to distortion of nucleolar and nuclear structures in HeLa cells. Biochem J, 415(3), 345-351.

Anderson, P., Kedersha, N., \& Ivanov, P. (2015). Stress granules, P bodies and cancer. Biochim Biophys Acta, 1849(7), 861-870.

Banjade, S., \& Rosen, M. K. (2014). Phase transitions of multivalent proteins can promote clustering of membrane receptors. eLife, 3.

Berry, J., Weber, S. C., Vaidya, N., Haataja, M., Brangwyyne, C. P. (2015). RNA transcription modulates phase transition-driven nuclear body assembly. Proc Natl Acad Sci U.S.A., 112(38), E5237-5245.

Boisvert, F. M., van Koningsbruggen, S., Navascues, J., Lamond, A. I. (2007). The multifunctional nucleolus. Nat Rev Mol Cell Biol, 8, 574-585.

Brangwynne, C. P., Eckmann, C. R., Courson, D. S., Rybarska, A., Hoege, C., Gharakhani, J., Jülicher, F., Hyman, A. A. (2009). Germline P granules are liquid droplets that localize by controlled dissolution/condensation. Science, 324(5935), 17291732.

Buchan, J. R. (2014). mRNP granules. Assembly, function, and connections with disease. RNA Biol, 11(8), 1019-1030.

Buchan, J. R., \& Parker, R. (2009). Eukaryotic stress granules: the ins and outs of translation. Mol Cell, 36, 932-941.

Burke, K. A., Janke, A. M., Rhine C. L., \& Fawzi, N. L. (2015). Residue-by-residue view of in vitro FUS granules that bind the C-terminal domain of RNA polymerase II. Mol Cell, 60, 231-241.

Cioce, M., \& Lamond, A. I. (2005). Cajal bodies: a long history of discovery. Annu Rev Cell Dev Biol, 21, 105-131.

Derenzini, M., Montanaro, L. \& Treré, D. (2009). What the nucleolus says to a tumour pathologist. Histopathology, 54(6), 752-762.

El Hajj, H., Dassouki, Z., Berthier, C., Raffloux, E., Ades, L., Legrand, O., Hleihel, R., Sahin, U., Tawil, N., Salameh, A., Zibara, K., Darwiche, N., Mohty, M., Dombret, H., 
Fenaux, P., de Thé, H., Bazarbachi, A. (2015). Retinoic acid and arsenic trioxide trigger degradation of mutated NPM1, resulting in apoptosis of AML cells. Blood, 125(22), 3447-3454.

Elbaum-Garfinkle, S., Kim, Y., Szczepaniak, K., Chen, C. C., Eckmann, C. R., Myong, S., Brangwynne, C. P. (2015). The disordered P granule protein LAF-1 drives phase separation into droplets with tunable viscosity and dynamics. Proc Natl Acad Sci U.S.A., 112, 7189-7194.

Falini, B., Nicoletti, I., Bolli, N., Martelli, M. P., Liso, A., Gorello, P., Mandelli, F., Mecucci, C., Martelli, M. F. (2007). Translocations and mutations involving the nucleophosmin (NPM1) gene in lymphomas and leukemias. Haematologica, 92(4), 519532.

Feric, M., Vaidya, N., Harmon, T. S., Mitrea, D. M., Zhu, L., Richardson, T. M., Kriwacki, R. W., Pappu, R. V., Brangwynne, C. P. (2016). Coexisting liquid phases underlie nucleolar subcompartments. Cell, 165(7), 1686-1697.

Fox, A. H., \& Lamond, A. I. (2010). Paraspeckles. Cold Spring Harb Perspect Biol, 2.

Frye, M., Dragoni, I., Chin, S. F., Spiteri, I., Kurowski, A., Provenzano, E., Green, A., Ellis, I. O., Grimmer, D., Teschendorff, A., Zouboulis, C. C., Caldas, C., Watt, F. M. (2010). Genomic gain of 5p15 leads to over-expression of Misu (NSUN2) in breast cancer. Cancer Lett. 289(1), 71-80.

Gamalinda, M., Ohmayer, U., Jakovljevic, J., Kumcuoglu, B., Woolford, J., Mbom, B., Lin, L., Woolford, J. L. Jr. (2014). A hierarchical model for assembly of eukaryotic 60S ribosomal subunit domains. Genes Dev, 28(2), 198-210.

Grisendi, S., Bernardi, R., Rossi, M., Cheng, K., Khandker, L., Manova, K., Pandolfi, P. P. (2005). Role of nucleophosmin in embryonic development and tumorigenesis. Nature, 437(7055), 147-153.

Grisendi, S., Mecucci, C., Falini, B. \& Pandolfi, P. P. (2006). Nucleophosmin and cancer. Nature Rev Cancer, 6, 493-505.

Guo, L., \& Shorter, J. (2015). It's raining liquids: RNA tunes viscoelasticity and dynamics of membraneless organelles. Mol Cell, 60, 189-192.

Han, T. W., Kato, M., Xie, S., Wu, L. C., Miraei, H., Pei, J., Chen, M., Xie, Y., Allen, J., Xiao, G., McKnight, S. L. (2012). Cell-free formation of RNA granules: bound RNAs identify features and components of cellular assemblies. Cell, 149, 768-779.

Hernandez-Verdun, D. (2011). Assembly and disassembly of the nucleolus during the cell cycle. Nucleus, 2, 189-194. 
Holmberg Olausson, K., Nistér, M. \& Lindström, M. S. (2014). Loss of nucleolar histone chaperone NPM1 triggers rearrangement of heterochromatin and synergizes with a deficiency in DNA methyltransferase DNMT3A to drive ribosomal DNA transcription. J Biol Chem, 289(50), 34601-34619.

Huang da, W., Sherman, B. T. \& Lempicki, R. A. (2009). Bioinformatics enrichment tools: paths toward the comprehensive functional analysis of large gene lists. Nucleic Acids Res, 37, 1-13.

Huttlin, E., Ting, L., Bruckner, R. J., Gebreab, F., Gygi, M. P., Szpyt, J., Tam, S., Zarraga, G., Colby, G., Baltier, K., Dong, R., Guarani, V., Vaites, L. P., Ordureau, A., Rad, R., Erickson, B. K., Wühr, M., Chick, J., Zhai, B., Kolippakkam, D., Mintseris, J., Obar, R. A., Harris, T., Artavanis-Tsakonas, S., Sowa, M. E., De Camilli, P., Paulo, J. A., Harper, J. W., Gygi, S. P (2015). The BioPlex Network: A systematic exploration of the human interactome. Cell, 162(2), 425-440.

Hyman, A. A., Weber, C. A., \& Jülicher, F. (2014). Liquid-liquid phase separation in biology. Annu Rev Cell Dev Biol, 30, 39-58.

Kang, M., Day, C. A., Kenworthy, A. K. \& DiBenedetto, E. (2012). Simplified equation to extract diffusion coefficients from confocal FRAP data. Traffic, 13, 1589-1600.

Kim, H. J., Kim, N. C., Wang, Y. D., Scarborough, E. A., Moore, J., Diaz, Z., MacLea, K. S., Freibaum, B., Li, S., Molliex, A., Kanagaraj, A. P., Carter, R., Boylan, K. B., Wojtas, A. M., Rademakers, R., Pinkus, J. L., Greenberg, S. A., Trojanowski, J. Q., Traynor, B. J., Smith, B. N., Topp, S., Gkazi, A. S., Miller, J., Shaw, C. E., Kottlors, M., Kirschner, J., Pestronk, A., Li, Y. R., Ford, A. F., Gitler, A. D., Benatar, M., King, O. D., Kimonis, V. E., Ross, E. D., Weihl, C. C., Shorter, J., Taylor, J. P. (2013). Mutations in prion-like domains in hnRNPA2B1 and hnRNPA1 cause multisystem proteinopathy and ALS. Nature, 495(7442), 467-473.

Li, P., Banjade, S., Cheng, H. C., Kim, S., Chen, B., Guo, L., Hollingsworth, J. V., King, D. S., Banani, S. F., Russo, P. S., Jiang, Q. X., Nixon, B. T., Rosen, M. K. (2012). Phase transitions in the assembly of multivalent signalling proteins. Nature, 483, 336-340.

Magoulas, C., Zatsepina, O. V., Jordan, P. W. H., Jordan, E. G. \& Fried, M. (1998). The SURF-6 protein is a component of the nucleolar matrix and has a high binding capacity for nucleic acids in vitro. Eur J Cell Biol, 75(2), 174-183.

Matsuo, Y., Granneman, S., Thomas, M., Manikas, R. G., Tollervey, D., Hurt, E. (2014). Coupled GTPase and remodelling ATPase activities form a checkpoint for ribosome export. Nature, 505(7481), 112-116.

Mitrea, D. M., Cika, J. C., Guy, C. S., Ban, D., Banerjee, P. R., Stanley, C. B., Nourse, A., Deniz, A. A., Kriwacki, R. W. (2016). Nucleophosmin integrates within the nucleolus 
via multi-modal interactions with proteins displaying R-rich linear motifs and rRNA. eLife, 5.

Mitrea, D. M., Grace, C. J., Buljan, M., Yun, M. K., Pytel, N. J., Satumba, J., Nourse, A., Park, C. G., Madan Babu, M., White, S. W., Kriwacki, R. W. (2014). Structural polymorphism in the N-terminal oligomerization domain of NPM1. Proc Natl Acad Sci U.S.A., 111(12), 4466-4471.

Mitrea, D. M., \& Kriwacki, R. W. (2016). Phase separation in biology; functional organization of a higher order. Cell Commun Signal, 14(1)

Molliex, A., Temirov, J., Lee, J., Coughlin, M., Kanagaraj, A. P., Kim, H. J., Mittag, T., Taylor, J. P. (2015). Phase separation by low complexity domains promotes stress granule assembly and drives pathological fibrillization. Cell, 163, 123-133.

Montanaro, L., Treré, D., \& Derenzini, M. (2008). Nucleolus, Ribosomes, and Cancer. Am J Pathol, 173(2), 301-310.

Nott, T. J., Petsalaki, E., Farber, P., Jervis, D., Fussner, E., Plochowietz, A., Craggs, T. D., Bazett-Jones, D. P., Pawzon, T., Forman-Kay, J. D., Baldwin, A. J. (2015). Phase transitions of a disordered nuage protein generates environmentally responsive membraneless organells. Mol Cell, 57, 9360947.

Patel, A., Lee, H. O., Jawerth, L., Maharana, S., Jahnel, M., Hein, M. Y., Stoynov, S., Mahamin, J., Saha, S., Franzmann, T. M., Pozniakovski, A., Poser, I., Maghelli, N., Royer, L. A., Weigert, M., Myers, E. W., Grill, S., Drechsel, D., Hyman, A. A., Alberti, S. (2015). A liquid-to-solid phase transition of the ALS protein FUS accelerated by disease mutation. Cell, 162, 1066-1077.

Pederson, T. (2011). The Nucleolus. Cold Spring Harb Prospect Biol, 3(3).

Romanova, L. G., Anger, M., Zatsepina, O. V. \& Schultz, R. M. (2006). Implication of nucleolar protein SURF6 in ribosome biogenesis and preimplantation mouse development. Biol Reprod, 75, 690-696.

Schneider, S. Q., \& Bowerman, B. (2003). Cell polarity and the cytoskeleton in the Caenorhabditis elegans zygote. Annu Rev Genet, 37, 221-249.

Sharma, A., Lyashchenko, A. K., Lu, L., Nasrabady, S. E., Elmaleh, M., Mendelsohn, M., Nemes, A., Tapia, J. C., Mentis G. Z., Shneider, N. A. (2016). ALS-associated mutant FUS induces selective motor neuron degeneration through toxic gain of function. Nat Commun, 7.

Su, X., Ditlev, J. A., Hui, E., Xing, W., Banjade, S., Okrut, J., King, D. S., Taunton, J., Rosen, M. K., Vale, R. D. (2016). Phase separation of signaling molecules promotes T cell receptor signal transduction. Science, 352(6285), 595-599. 
Tafforeau, L., Zorbas, C., Langhendries, J. L., Mullineux, S. T., Stamatopoulou, V., Mullier, R., Wacheul, L., Lafontaine, D. L. (2013). The complexity of human ribosome biogenesis revealed by systematic nucleolar screening of Pre-rRNA processing factors. Mol Cell, 51, 539-551.

Tajrishi, M. M., Tuteja, R. \& Tuteja, N. (2011). Nucleolin: The most abundant multifunctional phosphoprotein of nucleolus. Commun Integr Biol, 4(3), 267-275.

UniProt Consortium. (2014). Activities at the Universal Protein Resource (UniProt). Nucleic Acids Res, 42, D191-198.

Wang, D., Baumann, A., Szebeni, A., \& Olson, M. O. (1994). The nucleic acid binding activity of nucleolar protein B23.1 resides in its carboxyl-terminal end. J Biol Chem, 269(49), 30994-30998.

Weber, S. C., \& Brangwynne. (2012). Getting RNA and protein in phase. Cell. 149, 1188-1191.

Weber, S. C. \& Brangwynne, C. P. (2015). Inverse size scaling of the nucleolus by a concentration-dependent phase rransition. Curr Biol, 25(5), 641-646.

Zhang, H., Elbaum-Garfinkle, S., Langdon, E. M., Taylor, N., Occhipinti, P., Bridges, A. A., Brangwynne, C. P., Gladfelter, A. S. (2015). RNA controls polyQ protein phase transitions. Mol Cell, 60, 220-230. 


\section{APPENDIX A. PROTEIN PURIFICATION}

Table A-1. Protein Sequences

\begin{tabular}{|c|c|}
\hline Construct & Sequence \\
\hline \multirow[t]{4}{*}{ N130 } & GSWEDSMDMDMSPLRPQNYLFGCELKADKDYHFKVDNDENE \\
\hline & HQLSLRTVSLGAGAKDELHIVEAEAMNYEGSPIKVTLATLKMS \\
\hline & VQPTVSLGGFEITPPVVL \\
\hline & RLKCGSGPVHISGQHLVAVEEDAESEDEEE \\
\hline \multirow{7}{*}{$\mathrm{N} 294$} & GSHMEDSMDMDMSPLRPQNYLFGCELKADKDYHFKVDNDEN \\
\hline & EHQLSLRTVSLGAGAKDELHIVEAEAMNYEGSPIKVTLATLKM \\
\hline & SVQPTVSLGGFEITPPVVLRLKCGSGPVHISGQHLVAVEEDAESE \\
\hline & DEEEEDVKLLSISGKRSAPGGGSKVPQKKVKLAADEDDDDDDE \\
\hline & EDDDEDDDDDDFDDEEAEEKAPVKKSIRDTPAKNAQKSNQNG \\
\hline & KDSKPSSTPRSKGQESFKKQEKTPKTPKGPSSVEDIKAKMQASIE \\
\hline & KGGSLPKVEAKFINYVKNCFRMTDQEAIQDLWQWRKSL \\
\hline \multirow[t]{4}{*}{ RPL23a } & GSHMAPKAKKEAPAPPKAEAKAKALKAKKAVLKGVHSHKKK \\
\hline & KIRTSPTFRRPKTLRLRRQPKYPRKSAPRRNKLDHYAIIKFPLTTE \\
\hline & SAMKKIEDNNTLVFIVDVKANKHQIKQAVKKLYDIDVAKVNTL \\
\hline & IRPDGEKKAYVRLAPDYDALDVANKIGII \\
\hline \multirow[t]{3}{*}{ GNL2 } & GSHEKIFAKPEEQRKTLEEDVDDRAPSKKGKKRKAQREEEQEH \\
\hline & SNKAPRALTSKERRRAVRQQRPKKVGVRYYETHNVKNRNRNK \\
\hline & KKTNDSEGQKHKRKKFRQKQ \\
\hline \multirow[t]{3}{*}{ Nucleolin } & GSHKGFGFVDFNSEEDAKAAKEAMEDGEIDGNKVTLDWAKPK \\
\hline & GEGGFGGRGGGRGGFGGRGGGRGGRGGFGGRGRGGFGGRGG \\
\hline & FGGRGGGGDH KPQGKKTKF \\
\hline \multirow[t]{5}{*}{ SURF6 } & GSHMASLLAKDAYLQSLAKKICSHSAPEQQARTRAGKTQGSET \\
\hline & AGPPKKKRKKTQKKFRKREEKAAEHKAKSLGEKSPAASGARRP \\
\hline & EAAKEEAAWASSSAGNPADGLATEPESVFALDVLRQRLHEKIQ \\
\hline & $\begin{array}{l}\text { EARGQGSAKELSPAALEKRRRRKQERDRKKRKRKELRAKEKA } \\
\text { RKAFFATFAOFVVF }\end{array}$ \\
\hline & 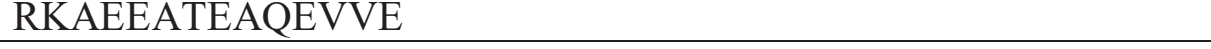 \\
\hline
\end{tabular}


A.

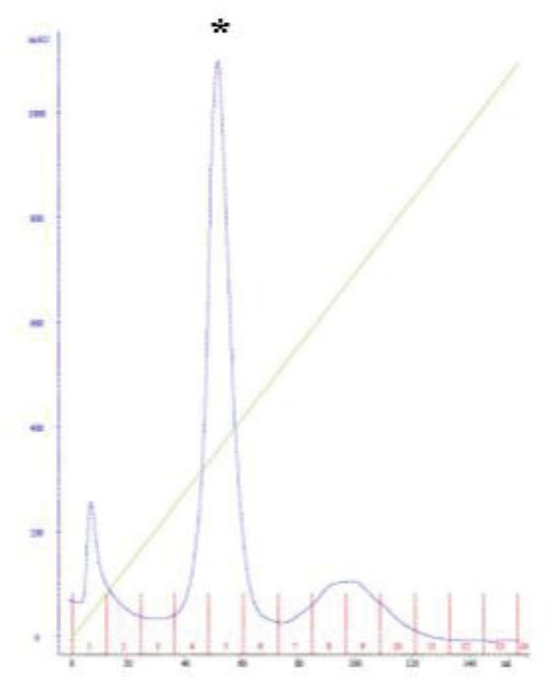

C.

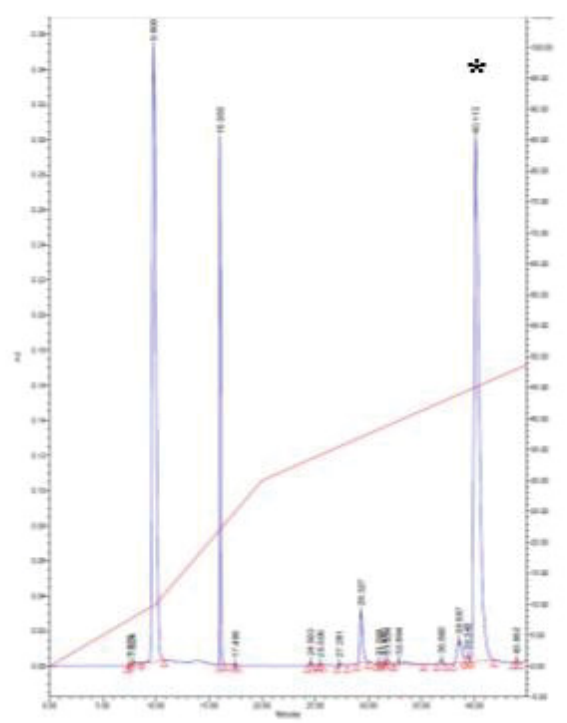

B.

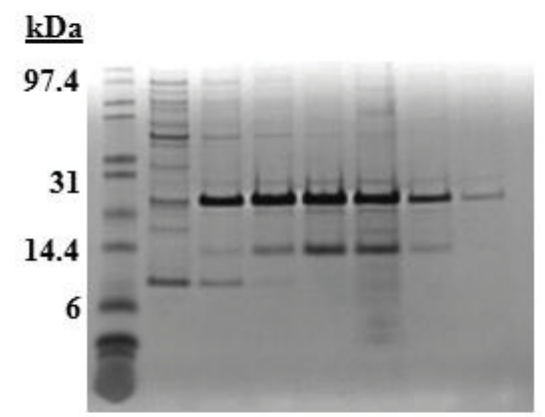

D.

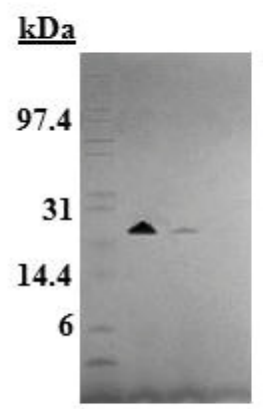

Figure A-1. RPL23a Protein Purification

A. Chromatogram from 6xHis-RPL23a purification by Ni-NTA affinity chromatography. RPL23a-containing fractions are labeled with as asterisk. B. SDS-PAGE gel of proteincontaining fractions eluted from Ni-NTA column. C. Chromatogram from RPL23a purification by HPLC. RPL23a-containing fractions are labeled with as asterisk. D. SDSPAGE gel of protein-containing fractions eluted from HPLC. Courtesy of Cheon-Gil Park. 
A.
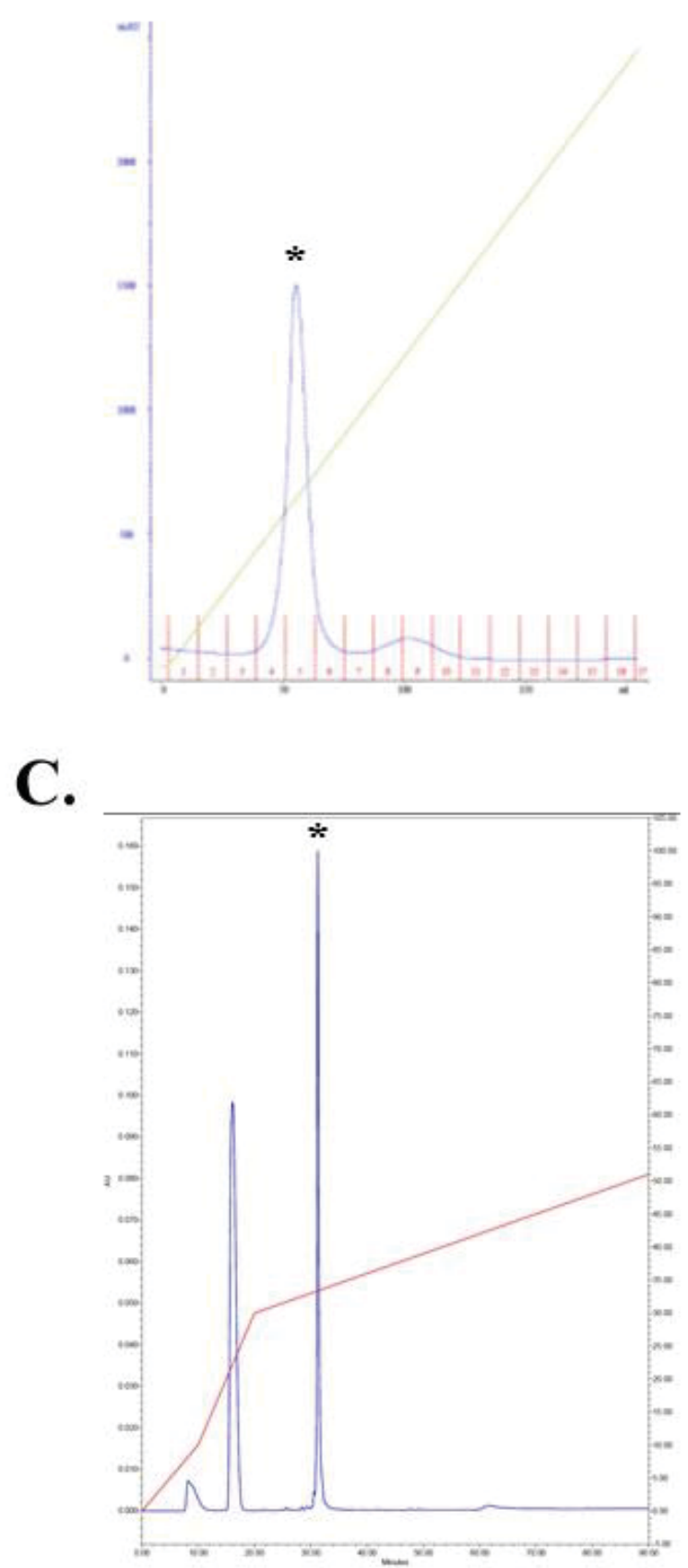

B.

$\underline{\mathrm{kDa}}$

97.4

31

14.4

6

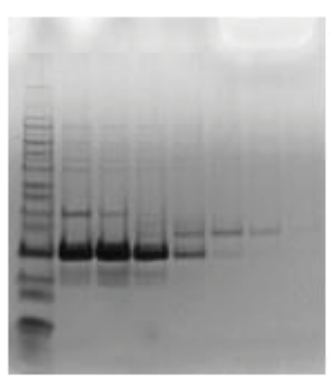

D.

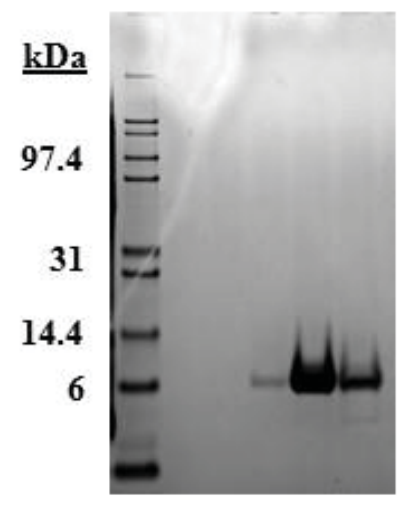

Figure A-2. Nucleolin Protein Purification

A. Chromatogram from $6 \mathrm{xHis}-\mathrm{Nucleolin}$ purification by Ni-NTA affinity chromatography. Nucleolin-containing fractions are labeled with as asterisk. B. SDSPAGE gel of protein-containing fractions eluted from Ni-NTA column. C.

Chromatogram from Nucleolin purification by HPLC. RPL23a-containing fractions are labeled with as asterisk. D. SDS-PAGE gel of protein-containing fractions eluted from HPLC. Courtesy of Cheon-Gil Park and Dr. Mylene Ferrolino. 
A.

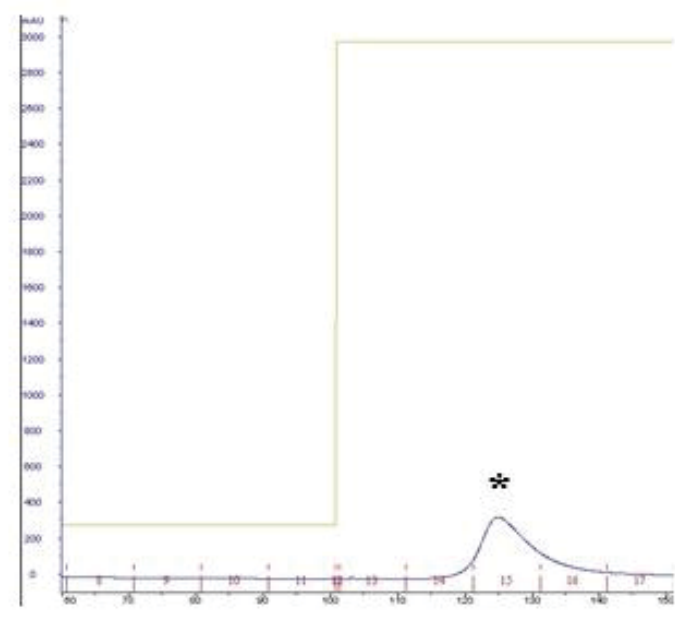

C.

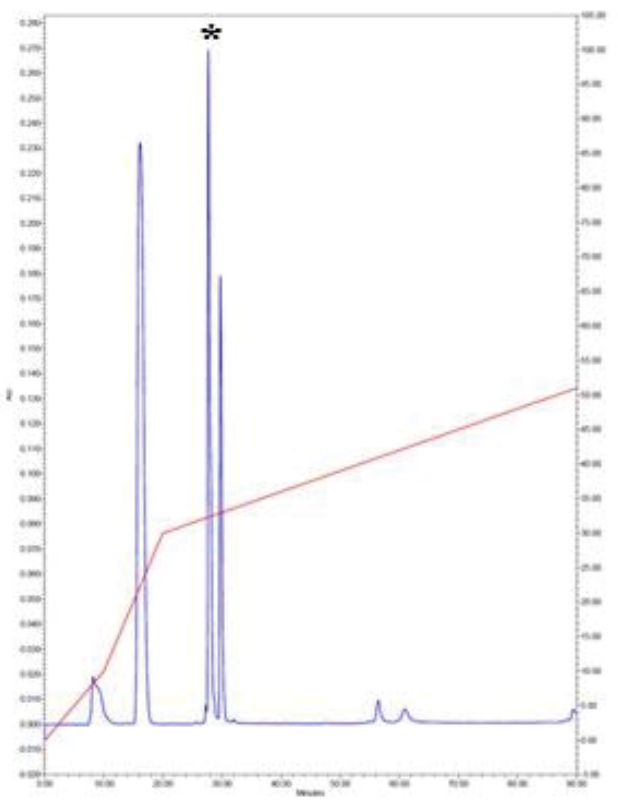

B.

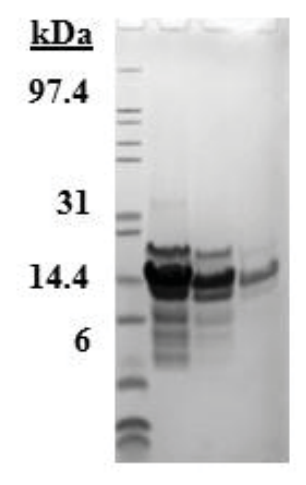

D.

\section{$\underline{\mathrm{kDa}}$}

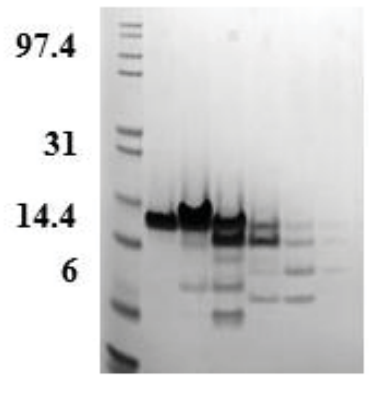

Figure A-3. GNL2 Protein Purification

A. Chromatogram from $6 x$ His-GNL2 purification by Ni-NTA affinity chromatography. GNL2-containing fractions are labeled with as asterisk. B. SDS-PAGE gel of proteincontaining fractions eluted from Ni-NTA column. C. Chromatogram from GNL2 purification by HPLC. GNL2-containing fractions are labeled with as asterisk. D. SDSPAGE gel of protein-containing fractions eluted from HPLC. Courtesy of Cheon-Gil Park and Dr. Mylene Ferrolino. 


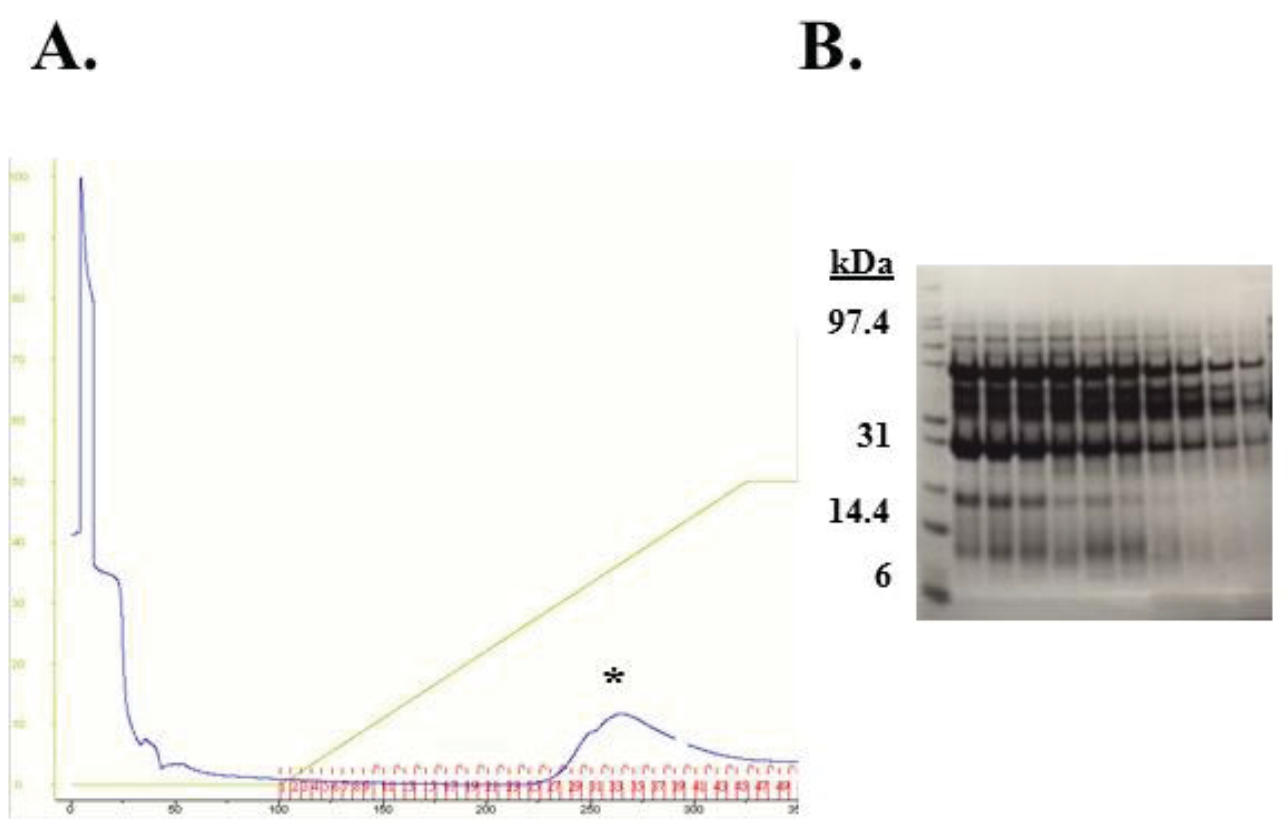

C.

D.

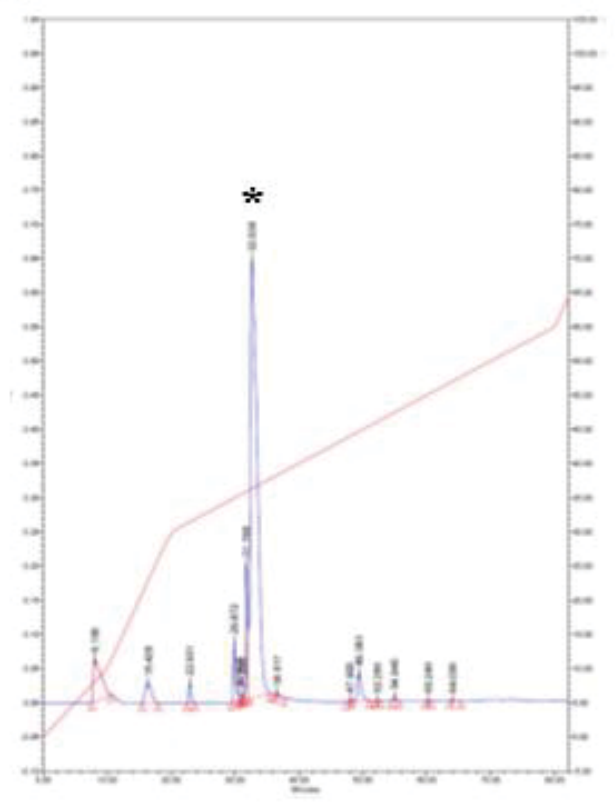

$\underline{\mathrm{kDa}}$

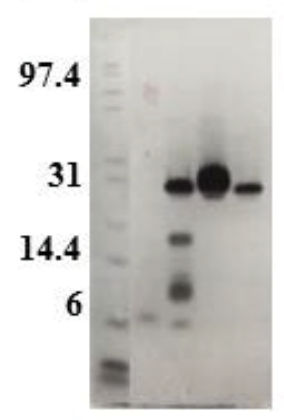

Figure A-4. SURF6 Protein Purification

A. Chromatogram from $6 x$ His-SURF6 purification by Ni-NTA affinity chromatography. SURF6-containing fractions are labeled with as asterisk. B. SDS-PAGE gel of proteincontaining fractions eluted from Ni-NTA column. C. Chromatogram from SURF6 purification by HPLC. SURF6-containing fractions are labeled with as asterisk. D. SDSPAGE gel of protein-containing fractions eluted from HPLC. 


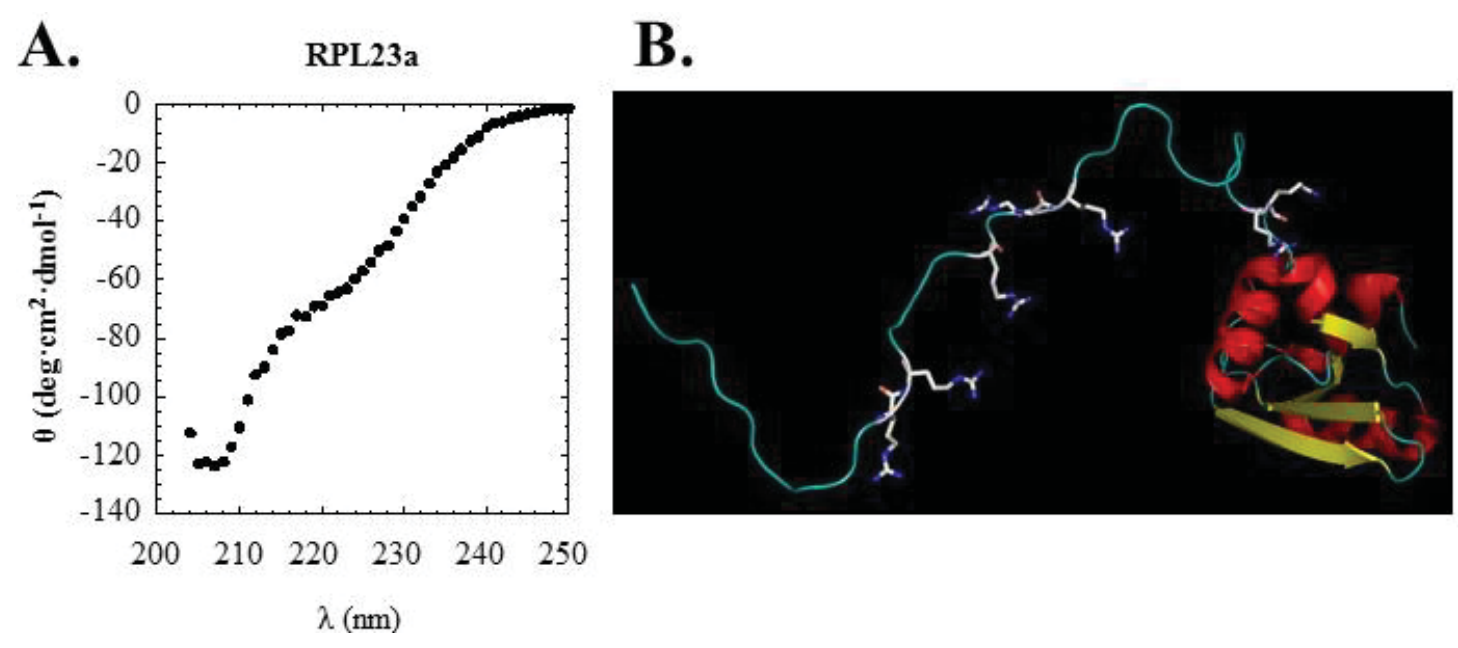

Figure B-1. RPL23a Structure Characterization

A. Purified RPL23a was refolded against $150 \mathrm{mM} \mathrm{NaCl}$ buffer. Proper refolding was confirmed by CD. RPL23a contains both $\beta$-sheet and helix structure as well as a disordered tail which was confirmed by peaks at $\sim 225 \mathrm{~nm}$ and $205 \mathrm{~nm}$, respectively. B. Crystal structure of RPL23a within the human 60S ribosomal subunit. (PDB ID 4V6X chain CX.)
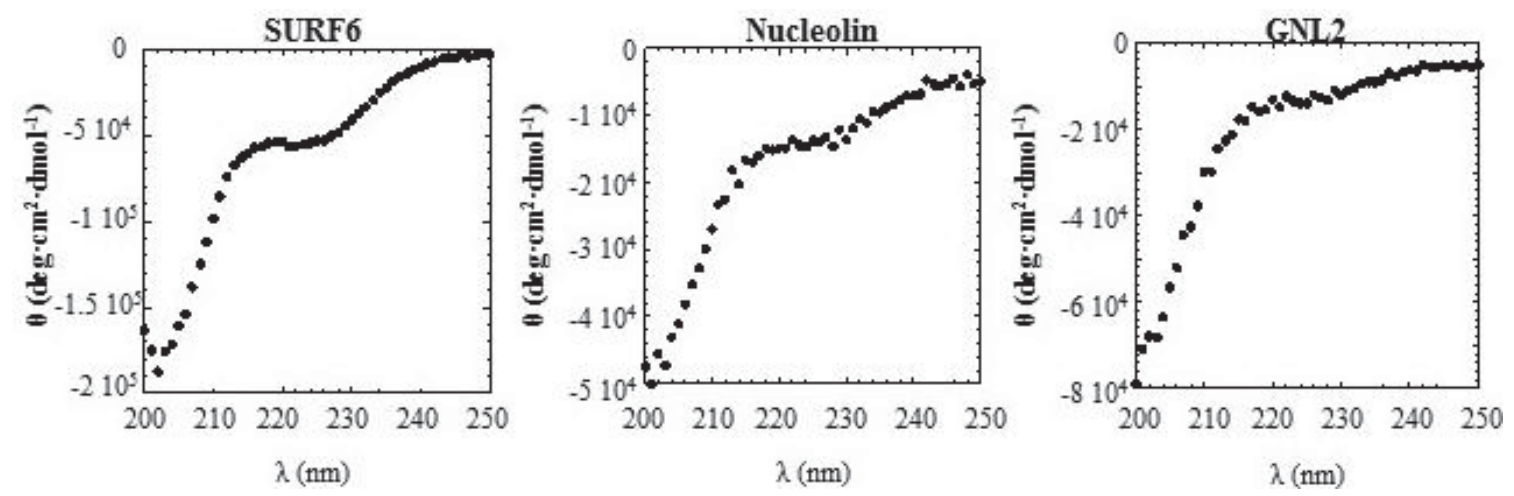

Figure B-2. CD Spectra of Purified R-Proteins

CD spectra of R-proteins in were collected and were buffer subtracted. SURF6 and Nucleoin appear to have some structured elements, but all of the proteins contain the predicted disordered elements. 
Table B-1. Protein Molecular Weight and Extinction Coefficients

\begin{tabular}{|c|c|c|}
\hline Construct & $\begin{array}{c}\text { Molecular Weight } \\
\text { (KDa) }\end{array}$ & $\begin{array}{c}\begin{array}{c}\text { Extinction Coefficient } \\
\left(\mathrm{M}^{-1} \mathrm{~cm}^{-1}\right)\end{array} \\
\end{array}$ \\
\hline RPL23a $a^{47-68}$ & 2.8 & 1,280 \\
\hline GNL2 ${ }^{682-709}$ & 3.6 & 2,560 \\
\hline SURF6 $6^{299-326}$ & 3.7 & 5,690 \\
\hline RPL5 $^{21-37}$ & 2.2 & 2,560 \\
\hline RPL5-RA & 2.1 & 2,560 \\
\hline RPL5-20L & 2.9 & 2,560 \\
\hline RPL5-16L & 2.6 & 2,560 \\
\hline N130 & 14.6 & 9,530 \\
\hline N122 & 13.6 & 3,840 \\
\hline N294 & 32.6 & 16,500 \\
\hline SURF $6^{1-182}$ & 20.2 & 6,970 \\
\hline GNL2 $2^{630-731}$ & 12.7 & 2,560 \\
\hline RPL23a $a^{1-156}$ & 18.0 & 6,400 \\
\hline Nucleolin ${ }^{610-709}$ & 10.4 & 5,690 \\
\hline
\end{tabular}

Molecular weights and extinction coefficients were calculated using the Scripps Protein Calculator freely available online (http://protcalc.sourceforge.net/). 


\section{VITA}

Jaclyn A. Cika was born in 1990 to James and Sandra Cika. In May of 2013, she graduated from Winthrop University in Rock Hill, South Carolina with a Bachelor of Science in Biochemistry. The following August, she entered into the Integrated Biomedical Sciences program at the University of Tennessee- Health Science Center, Memphis, Tennessee. In December of 2016, she will receive her Master of Science in Biomedical Sciences from the University of Tennessee. 